\title{
Multitemporal Accuracy and Precision Assessment of Unmanned Aerial System Photogrammetry for Slope-Scale Snow Depth Maps in Alpine Terrain
}

\author{
Marc S. Adams, ${ }^{1}$ (D) Yves Bühler, ${ }^{2}$ and Reinhard Fromm ${ }^{1}$
}

\begin{abstract}
Reliable and timely information on the spatio-temporal distribution of snow in alpine terrain plays an important role for a wide range of applications. Unmanned aerial system (UAS) photogrammetry is increasingly applied to cost-efficiently map the snow depth at very high resolution with flexible applicability. However, crucial questions regarding quality and repeatability of this technique are still under discussion. Here we present a multitemporal accuracy and precision assessment of UAS photogrammetry for snow depth mapping on the slope-scale. We mapped a $0.12 \mathrm{~km}^{2}$ large snow-covered study site, located in a high-alpine valley in Western Austria. 12 UAS flights were performed to acquire imagery at $0.05 \mathrm{~m}$ ground sampling distance in visible (VIS) and near-infrared (NIR) wavelengths with a modified commercial, off-the-shelf sensor mounted on a custom-built fixedwing UAS. The imagery was processed with structure-from-motion photogrammetry software to generate orthophotos, digital surface models (DSMs) and snow depth maps (SDMs). Accuracy of DSMs and SDMs were assessed with terrestrial laser scanning and manual snow depth probing, respectively. The results show that under good illumination conditions (study site in full sunlight), the DSMs and SDMs were acquired with an accuracy of $\leq 0.25$ and $\leq 0.29 \mathrm{~m}$ (both at $1 \sigma$ ), respectively. In case of poorly illuminated snow surfaces (study site shadowed), the NIR imagery provided higher accuracy $(0.19 \mathrm{~m} ; 0.23 \mathrm{~m})$ than VIS imagery $(0.49 \mathrm{~m} ; 0.37 \mathrm{~m})$. The precision of the $\mathrm{UAS}_{\mathrm{SDMs}}$ was $0.04 \mathrm{~m}$ for a small, stable area and below $0.33 \mathrm{~m}$ for the whole study site (both at $1 \sigma$ ).
\end{abstract}

Key words: Unmanned aerial vehicles, terrestrial laser scanning, manual snow depth probing, digital surface models, validation, error.

\section{Introduction}

The spatial distribution of snow depth in alpine environments is highly heterogeneous (Elder et al.

1 Department of Natural Hazards, Austrian Research Centre for Forests (BFW), Hofburg Rennweg 1, 6020 Innsbruck, Austria. E-mail: marc.adams@bfw.gv.at

2 WSL Institute for Snow and Avalanche Research SLF, Flüelastrasse 11, 7260 Davos Dorf, Switzerland.
1998). This is mainly owed to the complex interaction between alpine terrain and meteorological factors, such as precipitation and surface energy fluxes, as well as the redistribution of snow by wind, sloughing or avalanche activity (Cline et al. 1998; Elder et al. 1991). Area-wide approaches to determine snow depth [e.g., based on automatic weather station (AWS) data combined with medium-resolution satellite imagery (Foppa et al. 2007)] are not able to capture its high local variability (Ginzler et al. 2013). However, detailed information on slope-scale snow depth distribution plays an important role for many applications in snow science and practice, including numerical modelling of snow drift (Durand et al. 2005; Beyers et al. 2004), ecological studies on alpine flora and fauna (Bilodeau et al. 2013; Peng et al. 2010), planning avalanche hazard mitigation measures (Margreth and Romang 2010; Fuchs et al. 2007), avalanche forecasting and warning (Helbig et al. 2015; Vernay et al. 2015), avalanche event documentation, e.g., for hazard zone mapping (Holub and Fuchs 2009; Decaulne 2007), prediction and assessment of flood hazard resulting from snow melt (Painter et al. 2016; Schöber et al. 2014) or as an input for the optimisation of numerical simulation models in avalanche dynamics research (Fischer et al. 2015; Teich et al. 2014). Manually measuring this information in situ is labour-intensive, potentially hazardous or even impossible (Nolin 2010). Therefore, a wide range of terrestrial, airborne and spaceborne remote and close-range sensing techniques have been applied to retrieve digital surface models (DSMs)/snow depth maps (SDMs) at the slope-scale (Deems et al. 2013; Dietz et al. 2012; Rees 2006). One of the most recent techniques is unmanned aerial system (UAS) photogrammetry, 
which has quickly become a wide-spread method for geodata collection in different fields of earth science (Colomina and Molina 2014; Nex and Remondino 2013). This development has been fostered by the proliferation of easy-to-use UAS platforms and sensors, as well as recent progress in the field of computer vision [structure-from-motion (Koenderink and van Doorn 1991) and multi-view stereopsis (Furukawa and Ponce 2009)], considerably reducing requirements for photogrammetric processing of aerial imagery (Mancini et al. 2013). Despite some drawbacks (e.g., range limited to slope-scale, legal regulations, necessity for stable flight weather conditions), UAS photogrammetry offers many advantages over established techniques for snow depth mapping: compared to manned aircraft campaigns, UAS can acquire imagery at a much lower cost (e.g., for equipment, training, maintenance, operation) (Harder et al. 2016), higher operational flexibility (Vander Jagt et al. 2015), as well as higher flexibility and choice regarding the sensors' spatial and radiometric resolution, including an option for UAS-based laser scanning (Whitehead and Hugenholtz 2014); compared to terrestrial laser scanning (TLS), UAS photogrammetry is more flexible regarding deployment in alpine terrain [high-accuracy UAS positioning or point cloud registration routines as presented by Miziński and Niedzielski (2017) make georeferencing targets obsolete] and it does not suffer the limitations of the line-of-sight due to acute viewing angles or occlusions (Marti et al. 2016; Harder et al. 2016). However, while the abovementioned techniques are well-established, their quality and repeatability well-known (Hartzell et al. 2015; Müller et al. 2014), crucial questions regarding the accuracy and precision of UAS-based snow depth mapping are still under discussion (Avanzi et al. 2017). Several contributions have recently been published, reporting on the application of UAS photogrammetry to snow depth mapping, using both multicopter and fixed-wing UAS. In all of these studies, the UAS results were validated with reference data including:

i. Global navigation satellite system (GNSS) measurements of the snow surface and/or manual snow depth probing (MP) (Miziński and Niedzielski
2017; De Michele et al. 2016; Harder et al. 2016; Lendzioch et al. 2016; Bühler et al. 2016; Vander Jagt et al. 2015).

ii. Very high resolution optical satellite imagery (Marti et al. 2016).

iii. A large-frame aerial camera mounted on a manned aircraft (Boesch et al. 2016).

iv. A multi station in scanning mode (Avanzi et al. 2017).

However, all these assessments were made based on a comparatively small number of UAS measurements (1-3 flights), except for Harder et al. (2016); the majority used small amounts of discrete samples (GNSS and MP measurements); most studies evaluated the use of imagery collected in the visible part of the spectrum (VIS) (except for Miziński and Niedzielski 2017; Bühler et al. 2016; Boesch et al. 2016), however, several authors have pointed to the benefits of using near-infrared (NIR) imagery for snow mapping (Bühler et al. 2015; Nolin and Dozier 2000). Nolan et al. (2015) performed a large-scale accuracy and precision assessment of imagery collected with a consumer-grade digital camera mounted on a manned aircraft over large areas, with GNSS and airborne laser scanning data. However, since the employed methodology differs substantially from the presented study (size of target area, georeferencing routine, employed platform), results were not directly compared.

In this contribution, we present a multitemporal assessment (12 UAS flights) of the accuracy and precision of UAS photogrammetry for snow depth mapping. Adding to findings from the above-mentioned studies, we used TLS data to assess the accuracy of $\mathrm{UAS}_{\mathrm{DSM}}$, MP as reference data for $\mathrm{UAS}_{\mathrm{SDM}}$ accuracy and calculated precision by intercomparison of UAS results. VIS and NIR imagery was used to map snow depth with a fixed-wing UAS.

\section{Materials and Methods}

\subsection{Study Site}

The study site is located in the Tuxer Alps of North Tyrol, Austria $\left(47^{\circ} 10^{\prime} \mathrm{N} ; 11^{\circ} 38^{\prime} \mathrm{E}\right)$, between the Northern Calcareous Alps and the Main Alpine 
Ridge. It lies at approximately $2020 \mathrm{~m}$ a.s.l., near the head of a north-south running valley. The area features a typical inner-alpine climate, with annual precipitation between 1200 and $1700 \mathrm{~mm}$ (period 1983-2003) and snow depths of 1-2 m (Schaffhauser and Fromm 2008). The land cover of the site is mainly characterised by (partially boggy) alpine grasslands, mixed with various types of small scrubs (height $<1 \mathrm{~m}$ ). In the west and north, large clusters of dwarf pine (Pinus mugo, height 1-3 m) and singular or groups of stone pine (Pinus cembra) are present. Several small streams run parallel to the valley axis, some of which drain into a pond (approximate size $0.006 \mathrm{~km}^{2}$ ) in the north. The topography of the site (mean slope angle $6^{\circ}$ ) is dominated by the flat valley bottom; the steepest areas lie in the east and west, where the lower sections of the adjoining slopes reach into the study site. Large boulders (max. width $<30 \mathrm{~m}$, max. height $<5 \mathrm{~m}$ ) are scattered in the centre of the site. Multiple small buildings are situated in the north and east, connected by a network of gravel roads, which are partially cleared in winter. An overview of the site is provided in Fig. 1; it highlights where TLS, UAS and MP data were collected, as well as the location of the AWS and reference points (RPs). The site was chosen on account of its good accessibility, even during periods with high avalanche danger, and well-established infrastructure (power supply and network connection) (Adams et al. 2016).

\subsection{Data Acquisition and Processing}

We collected data at the study site during four measurement campaigns in 'snow-on' conditions in February and March 2015 (Fig. 2, upper image). This allowed us to take different snow pack properties (snow depth, snow type at surface) and illumination conditions at the study site into account. For example, the snow depth measured at the AWS, ranged between $0.68 \mathrm{~m}$ (13 February, 1 p.m.) and $1.01 \mathrm{~m}$ (3 March, 2 a.m.).

Each campaign consisted of:

- Two to four UAS flights.

- One to two TLS scans.

- 149 MP measurements (February campaigns only).
The UAS and TLS data were acquired over an area of interest (AOI) of $0.12 \mathrm{~km}^{2}$ (Fig. 1). It was located in the centre of the valley floor, where MP measurements were performed, too. Due to the geometric properties of the measurement setup, TLS data was only collected on $70 \%$ of the area of the core AOI (not considering occlusions). Reference 'snow-off' UAS imagery was acquired on 21 August 2015.

\subsubsection{Unmanned Aerial Systems}

The aerial imagery was collected with a Multiplex Mentor Elapor fixed-wing UAS (Fig. 2-lower image, Table 1) at different times of the day. The original Mentor model was modified to add UAS capabilities, it was fitted with navigation sensors to determine its absolute position (GNSS) and orientation (inertial measurement unit); this data was managed by the on-board autopilot for autonomous flight (3DR ArduPilotMega); pre-flight mission planning to define the flight path, height and speed was performed in the open-source software Mission Planner (Table 2); an additional on-board GNSS unit (SM GPS-Logger 2) recorded $10 \mathrm{~Hz}$ positional data $(x, y$ and $z$ ). After completing each flight, the onboard GNSS data was synchronised with the recorded imagery (geotagging), to facilitate the image processing (Adams et al. 2016). The UAS had a maximum flight time of $40 \mathrm{~min}$, during which it could map up to $0.6 \mathrm{~km}^{2}$ at $2,000 \mathrm{~m}$ a.s.l. in wintry conditions.

A Sony NEX5R digital camera was installed in the UAS fuselage to record the imagery on all the flights. It weighed $0.4 \mathrm{~kg}$ and was fitted with a $50 \mathrm{~mm}$ Sony prime lens $(0.2 \mathrm{~kg})$. The camera's 16-megapixel APS-C sensor was modified by removing the built-in short-pass filter, increasing its sensitivity in the near-infrared from 700 to $1100 \mathrm{~nm}$. This allowed us to mount the lens with different notch filters to record data in various parts of the electromagnetic spectrum: VIS $(\lambda=350-680 \mathrm{~nm}), \quad$ NIR700 $(\lambda>700 \mathrm{~nm})$ and NIR830 $(\lambda>830 \mathrm{~nm})$. Each flight was carried out with a single camera on-board the UAS, set to record imagery at a defined wavelength, and the filters changed between retrievals. The camera was 


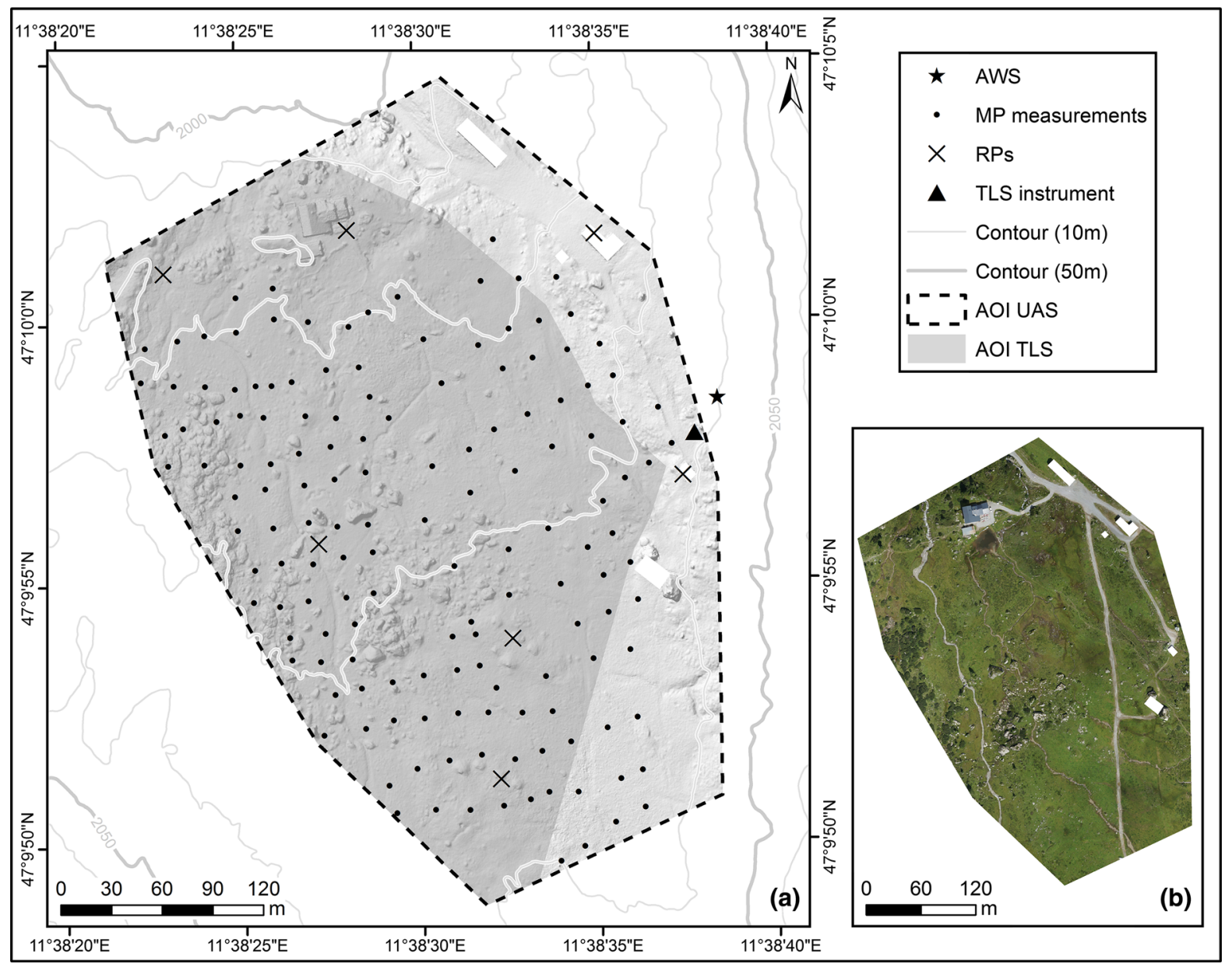

Figure 1

Study site overview; a outline of areas of interest (AOI) for UAS and TLS data acquisition, as well as points where MP measurements were performed; positions of instruments (TLS and AWS) and RPs; 10 and $50 \mathrm{~m}$ contour lines were derived from airborne laser scanning data; 'snow-off' reference data included as hillshaded $\mathrm{UAS}_{\mathrm{DSM}}$ [background of a] and orthophoto (b)

triggered via infrared signal, recording images at $1.25 \mathrm{~Hz}$. Basic camera settings were fixed pre-flight, as no telemetry was available (Table 2); imagery was recorded with manual focus. The high image overlap (80\% along- and 90\% cross-track) was chosen based on the authors' own experience, as well as recommendations from authors of similar studies dealing with UAS-based mapping of low contrast surfaces (Harder et al. 2016; Klemas 2015). We performed no internal camera calibration.

The study site was surrounded by high peaks, which cast a shadow on the valley floor from 1 p.m. onwards. This allowed a direct comparison of imagery collected in good (full sunlight) and in poor illumination conditions (shadow) on the same day. During all the campaigns, the sky was clear or only partially cloudy, with no precipitation; the nearby AWS (located at $2041 \mathrm{~m}$ a.s.1.) recorded the air temperatures between $-8^{\circ}$ and $5{ }^{\circ} \mathrm{C}$, at only very light winds $\left(V_{\max }<3 \mathrm{~m} \mathrm{~s}^{-1}\right) 7 \mathrm{~m}$ above ground level. These can be considered good weather conditions for our UAS flights, especially considering the alpine environment. However, higher wind speeds and lower air temperatures can be expected at our typical flight height (400 m above ground level).

In lieu of survey-grade GNSS sensors on-board the UAS, indirect georeferencing had to be used (Harwin et al. 2015; Vander Jagt et al. 2015). 

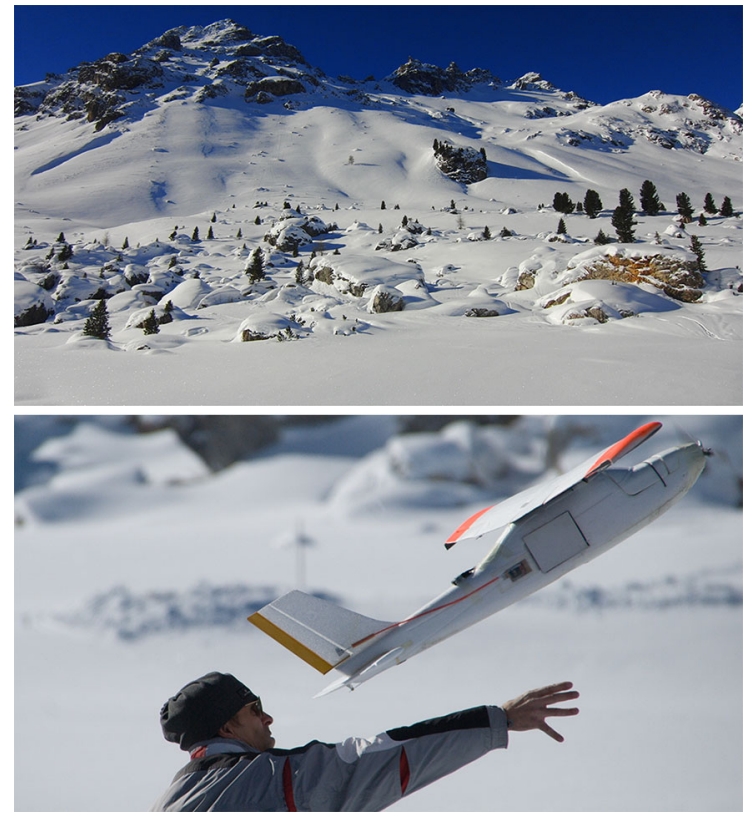

Figure 2

Central part of study site on 11 February 2015 (upper image); launching Mentor UAS (lower image)

Table 1

Technical specifications of the Mentor UAS (Adams et al. 2016)

\begin{tabular}{ll}
\hline UAS type & Fixed-wing (custom-built) \\
Dimensions & $1.6 \mathrm{~m}$ (wing span) \\
& $1.2 \mathrm{~m}$ (fuselage) \\
Engine & 1 electrical, brushless motor \\
Flight time & $30-40 \mathrm{~min}$ \\
Max. & $1500 \mathrm{~m} / 0.6 \mathrm{~km}^{2}$ \\
$\quad$ range/coverage & \\
Empty weight & $2.3 \mathrm{~kg}$ \\
Max. take-off & $2.8 \mathrm{~kg}$ \\
weight & \\
Max. payload & $0.5 \mathrm{~kg}$ \\
$\quad$ weight & 3DR APM 2.6 (IMU, barometer) \\
Navigation & 3DR uBlox GNSS with Compass Kit uBlox \\
& LEA-6H module \\
Wireless & Graupner MX-20 HOTT 2,4 GHz (sender) \\
$\quad$ communication & Frequency 2400 ... 2484.5 MHz \\
& Graupner GR-16 HOTT 2.4 GHz (receiver) \\
LiPo battery & LiPolice GreenLine Light Edition 5s \\
& 4900 mAh (0.6 kg) \\
\hline
\end{tabular}

Therefore, prior to each campaign, we distributed 10-20 RPs, consisting of $0.4 \times 0.4 \mathrm{~m}$ black-andwhite checkered wooden boards, within the AOI. We
Table 2

Typical UAS flight and camera settings
Overlap (along-/cross-track)

Flight height

Flight speed

Image format

Brightness compensation (fixed)

Exposure (fixed)

ISO (automatic)

Aperture (automatic)

\section{$80 / 90 \%$}

$400 \mathrm{~m}$ above ground level $12-14 \mathrm{~m} \mathrm{~s}^{-1}$ JPEG (high quality) 0 1/320-1/800 $100-400$ f/2.5-18 surveyed the location of each RP using a Trimble GEO-XT 2008, with an expected accuracy in the decimetre range (Adams et al. 2016). The data was corrected real time in the field and differentially during post-processing. Final RP coordinates were averaged from more than 200 point measurements made at each RP location. However, the resulting overall georeferencing errors (especially in $z$-direction) proved too high and resulted in implausible SDMs. Therefore, the $z$ values used for georeferencing the 'snow-off' $\mathrm{UAS}_{\mathrm{DSM}}$ were extracted from an airborne laser scanning DSM from 2009, while retaining the $x$ - and $y$-coordinates surveyed with the GNSS. To georeference the 'snow-on' UAS $\mathrm{USM}_{\mathrm{DS}}$, seven natural or man-made RPs were chosen. These RPs had remained snow-free throughout the winter (e.g., centre of flat stones in the river bed, corner of wooden patio outside hut) (Fig. 1). Their coordinates were extracted from the 'snow-off' UAS data. Thus, the 'snow-on' data could be referenced using a stable set of RPs, ensuring minimal systematic error introduced by the georeferencing procedure (Adams et al. 2016). However, this resulted in a comparatively small amount of seven RPs.

All the UAS imagery was processed with Agisoft's PhotoScan Pro (version 1.2.3), a commercially available photogrammetric software suite, that is widely used in the UAS community (Tonkin et al. 2014). It is credited to be among the most reliable (Sona et al. 2014) and accurate (Gini et al. 2013) software packages available. PhotoScan is based on a structure-from-motion algorithm (Verhoeven 2011) and provides a complete, photogrammetric workflow, with particular emphasis on multi-view stereopsis (Harwin et al. 2015). This workflow consists of the following principal steps (Vander Jagt et al. 2015): 
i. Tie-point matching.

ii. Bundle adjustment (constrained by assigning high weights to the RP coordinates).

iii. Linear seven-parameter conversion; removal of nonlinear deformations.

iv. Dense point cloud generation with multi-view stereo reconstruction.

v. Triangulation of dense point cloud into mesh, subsequently generating DSM and orthophotos.

In a related study, Boesch et al. (2015) analysed PhotoScan's suitability for snow depth mapping and the best combination of processing parameters. Therefore, all the imagery was processed with the following alignment parameters: accuracy-highest, pair selection-reference, key point limit-40,000, tie-point limit-10,000. The dense point cloud was generated with the settings: quality-medium, depth filtering-moderate. One of the main reasons for corrupt UAS imagery is motion blur, which results from shutter speeds that are too slow in relation to the movement of the UAS (Turner et al. 2015; Immerzeel et al. 2014). This applies in particular to motion in direction of the UAS' roll-axis, resulting from crosswinds, and increases with the length of the camera lens (Morgenthal and Hallermann 2016). As reported in Bühler et al. (2016), in our experience, fixed-wing UAS are generally more susceptible to crosswinds and thus less stable in windy conditions, than some multicopters. The sensor on-board our fixed-wing UAS was not stabilised by a gimbal. To systematically evaluate our imagery, we routinely calculated the 'quality index' (QI) during pre-processing in PhotoScan (Adams et al. 2016). As reported in the PhotoScan documentation (Agisoft 2016), it provides a normalised value for the sharpness of the imagery; images with $\mathrm{QI}<0.5$ are recommended to be excluded from photogrammetric processing. Orthophotos and DSM were exported from PhotoScan in 0.05 and $0.2 \mathrm{~m}$ resolution, respectively. We calculated snow depth for each pixel by subtracting the 'snow-off' DSM from the 'snow-on' DSM. This follows the definition by Fierz et al. (2009), where snow depth is the vertical distance from the base to the surface of the snow pack.

\subsubsection{Terrestrial Laser Scanning}

We used two Riegl long-range TLS instruments to collect the validation data: a LPM-321 (Fig. 3-left image) and a LPM 98-2k (Fig. 3-right image). Both the instruments operate at $905 \mathrm{~nm}$ wavelength, therefore, the penetration depths into the snow surface are only a few millimetres (Dozier and Painter 2004). They were positioned in a purposebuilt shed, overlooking the valley (Fig. 1), and set to map the valley floor in a single scan window. The LPM-321 was used for the first campaign; for the subsequent campaigns, the LPM 98-2k was installed in a fixed, weatherproof transparent glass fibre enclosure. We set up the LPM 98-2k to continuously and automatically acquire scans from the study site approximately every $6 \mathrm{~h}$, and a datalink allowed remote access [detailed setup description and technical specifications of the TLS instruments are provided in Adams et al. (2016)].

To georeference the TLS data, five RPs, consisting of $0.3-0.5 \mathrm{~m}$ rectangular aluminium plates, coated with highly reflective material, were installed in the target area prior to the UAS campaigns. Their positions were surveyed with a Trimble M3 total station [expected accuracy $\pm 0.002 \mathrm{~m} \quad(1 \sigma)$, plus 2 ppm distance dependent error]. The RPs were scanned by the TLS instrument before and after mapping the valley floor. Point clouds from both the TLS instruments were processed in RiPROFILE (version 1.5.7). Here the locations of the RPs in the global coordinate system and the scanner-own coordinate system were linked by minimising the standard deviation of the residues. An unfavourable geometry of the measurement setup and the inherent scanning routine of the instruments caused inhomogeneous point distances. To counter this distant dependent point density, mean $z$ values were calculated within a $0.2 \mathrm{~m}$ raster (corresponding to $\mathrm{DSM}_{\mathrm{UAS}}$ resolution) and the raster centre location plotted for validation. The accuracy assessment of the $\mathrm{UAS}_{\mathrm{DSMs}}$ was performed with $\mathrm{TLS}_{\mathrm{DSMs}}$, not the calculated snow depth values. No additional co-registration of these DSMs was performed. 

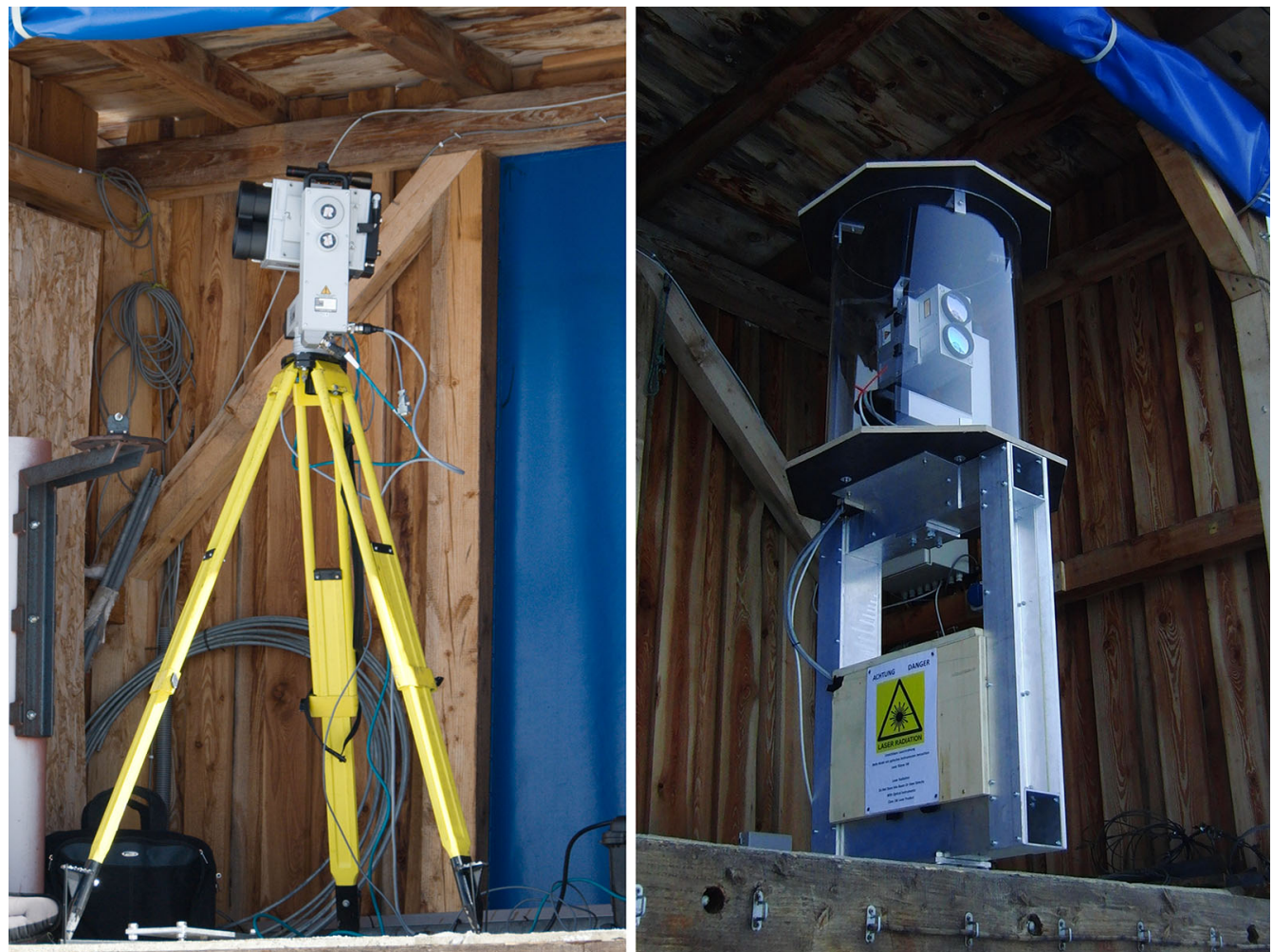

Figure 3

TLS instruments Riegl LPM-321 (left image) and LPM 98-2k (right image) in operation at the study site on 11 February 2015 and 13 February 2015, respectively (Adams et al. 2016)

\subsubsection{Manual Snow Depth Probing}

MP measurements were performed during both the February campaigns. The snowpack was sounded at each checkpoint with an avalanche probe. The checkpoints were distributed randomly within the AOI, roughly following a grid pattern to avoid spatial bias. At each checkpoint, five measurements were performed by probing all the four corners and the centre of a $2 \times 2 \mathrm{~m}^{2}$. The snow depths were recorded to the nearest centimetre. Additionally, a GNSS (Garmin GPSMap 64s) was used to record the geographic coordinates of the square's centre. The data was collected after completing campaign one, but is assumed to also be valid for campaign two, as the AWS recorded no intervening snowfall, and snow melt/settling was minimal $(0.03 \mathrm{~m})$. For validating the UAS-based snow depth maps, the centre location of the MP checkpoints was corrected by plotting them on the UAS orthophotos and manually adjusting their position. This was necessary as the Garmin GNSS has a nominal accuracy of only $\pm 3 \mathrm{~m}$ [1 standard deviation $(\sigma)$ ]. Additionally, it ensured the correct position of the checkpoints relative to the UAS results. To minimise the effect of the micro-topography below the snowpack on the results, the mean value of the five measurements was calculated. For accuracy assessment, the $\mathrm{UAS}_{\mathrm{SDM}}$ values of all the pixels within a $2 \mathrm{~m}$ radius around a checkpoint were averaged (Adams et al. 2016).

\subsection{Accuracy and Precision Assessment}

To evaluate the performance of the UAS for slope-scale snow depth mapping in alpine terrain, we need to answer the following questions: (i) How well do the UAS-based DSMs and SDMs correspond to measurements taken with established, state-of-the-art techniques? (ii) How reliable are the UAS results in terms of their reproducibility? These questions 
correspond to determining the accuracy and precision of the UAS results, respectively (Nolan et al. 2015).

\subsubsection{Accuracy}

Two reference data sets were used for accuracy assessment:

1. The TLS measurements allowed an assessment of $\mathrm{UAS}_{\mathrm{DSM}}$ accuracy at high spatial resolution (mean point distance: $0.2 \mathrm{~m}$ ). The TLS instruments effectively surveyed a very large number of (pseudo-) checkpoints within the AOI, at high accuracy; the LPM-321 operates at a nominal accuracy of $\pm 0.025 \mathrm{~m} \quad(1 \sigma)$ plus a distance dependent error of $\leq 20 \mathrm{ppm}$ (Grünewald et al. 2010; Riegl 2010); the LPM 98-2k at $\pm 0.05 \mathrm{~m}$ $(1 \sigma)$, plus a distance dependent error of $\leq 20 \mathrm{ppm}$ (Schaffhauser et al. 2008; Riegl 2006). Considering all the areas surveyed by the TLS are within $300 \mathrm{~m}$ range of the instruments, the nominal TLS accuracy is between \pm 0.031 and $\pm 0.056 \mathrm{~m}(1 \sigma)$ for LPM-321 and LPM 98-2k, respectively. However, these values assume that the area illuminated by the laser beam (the footprint) is circular; this implies an incidence angle $\theta=0^{\circ}$ on a planar surface (Prokop 2008). $\theta$ is defined as the angle between the vector normal to the measured surface and the incoming laser beam (Jörg et al. 2006). The size of the footprint $(\delta)$ generally increases with an increase of distance from the instrument, beam divergence and $\theta$ (when only considering planar surfaces) (Prokop et al. 2008). According to Jörg et al. (2006), $\delta$ remains below $1 \mathrm{~m}$ in diameter for close range $(<500 \mathrm{~m})$ TLS measurements, even at unfavourable scanning angles (i.e., $\theta<75^{\circ}$ ). In the present case, the TLS instrument surveys the valley floor from a small mound at the base of the slope east of the AOI, resulting in high $\theta\left(>75^{\circ}\right)$ and thus large $\delta$ values ( $>1 \mathrm{~m}$ diameter). Therefore, we calculated $\theta$ and the resulting $\delta$ for the 11 February 2015 TLS data set (change in snow depth and the position of the TLS to the following campaigns were considered negligible). Subsequently, the correlation between $\delta$ and $\mathrm{UAS}_{\mathrm{DSM}}$ error was determined. Following the general practice in statistics, the Bravais-
Pearson correlation coefficient $r$ was calculated for normally distributed data and the Spearman's rank correlation coefficient $r_{\mathrm{SP}}$ for non-normally distributed data (Fahrmeir et al. 2011).

2. The MP measurements were the basis for the assessment of the UAS $\mathrm{SDM}_{\mathrm{SD}}$ accuracy. Snow depth values were surveyed at comparatively low spatial resolution (mean distance between checkpoints: $18 \mathrm{~m}$ ). However, this data has a high vertical accuracy, as a majority of the checkpoints were located above the frozen ground; the penetration depth of the probe is therefore considered to be within $\pm 0.02 \mathrm{~m}$. Similar values are reported in comparative studies (e.g., Harder et al. 2016; Nolan et al. 2015). As this area is an unmanaged (high-) alpine grassland, it features a jagged micro-topography with local terrain height variations in the decimetre range. However, the high ground sampling distance of the $\operatorname{UAS}_{\text {DSMs }}(0.2 \mathrm{~m})$ and the MP sampling routine (Sect. 2.2.3) are considered to be able to account for these variations.

Authors of the comparable studies (e.g., Fras et al. 2016; Hugenholtz et al. 2013; Harder et al. 2016) used checkpoints surveyed with high-accuracy GNSS as reference data. Such data are not included in the presented study, as it focusses on the area-wide, multitemporal evaluation of UAS-based photogrammetry of snow-covered surfaces with TLS. Such a comparison has only been marginally covered in the literature published to date (Sect. 1). Additionally, MP data was included for a direct assessment of the UAS' snow depth mapping accuracy. This study focusses on vertical accuracy assessment, as no planimetric offset could be derived from MP or TLS data. Thus, the error of the UAS results was calculated as a difference in $z$ value between UAS and the reference data sets (Müller et al. 2014).

We followed the accuracy assessment procedure outlined in Höhle and Höhle (2009), which was also adapted in similar studies [e.g., Fras et al. (2016) and Müller et al. (2014)]. Thus, the normality of UAS $\mathrm{USM}_{\mathrm{DSM}}$ and $\mathrm{UAS}_{\mathrm{SDM}}$ error distributions was checked by visually interpreting their histograms and quantilequantile (Q-Q) plots. Q-Q plots juxtapose theoretical quantiles of a normal distribution with the quantiles 
Table 3

Accuracy measures applied to normally (A) and non-normally (B) distributed errors; $n$ is the number of tested points, and $\Delta h_{i}$ denotes the difference from reference data for a point i (Höhle and Höhle 2009)

\begin{tabular}{ll}
\hline Accuracy measure & Notational expression \\
\hline A & $\mathrm{ME}(\mu)=\frac{1}{n} \sum_{i=1}^{n} \Delta h_{i}$ \\
Mean error & $\mathrm{SD}=\sqrt{\frac{1}{(n-1)} \sum_{i=1}^{n}\left(\Delta h_{i}-\mu\right)^{2}}$ \\
Standard deviation & \\
& $\mathrm{MAE}=\frac{\sum_{i=1}^{n}\left|\Delta h_{i}\right|}{n}$ \\
Mean absolute error & \\
Root mean square error & $\mathrm{RMSE}=\sqrt{\frac{1}{n} \sum_{i=1}^{n} \Delta h_{i}^{2}}$ \\
B & \\
50\% quantile (median) & $Q_{\Delta h}(0.5)=m_{\Delta h}$ \\
68.3\% quantile & $Q_{|\Delta h|}(0.683)$ \\
95\% quantile & $Q_{|\Delta h|}(0.95)$ \\
Normalised median & $\mathrm{NMAD}=1.4826 \operatorname{median}_{i}\left(\left|\Delta h_{i}-m_{\Delta h}\right|\right)$ \\
$\quad$ absolute deviation & \\
\hline
\end{tabular}

of the empirical distribution function. If the latter is normally distributed, the Q-Q plot will result in a straight line; strong deviation indicates non-normal distribution (Höhle and Höhle 2009). Additionally, skewness and kurtosis were calculated. Based on recommendations from Höhle and Höhle (2009) and Willmott and Matsuura (2006), different accuracy measures were applied to normally and non-normally distributed errors (Table 3).

All the data sets were referenced to and compared within common global projected planimetric (MGI Austria GK West; EPSG Code 31254) and vertical coordinate systems (Gebrauchshöhen Adria; WKID 5778).

\subsubsection{Precision}

Performing several UAS flights per campaign day allowed assessing the precision, i.e., the reproducibility of the UAS results. As argued by Fabris and Pesci (2005) and Nolan et al. (2015), precision assessment of photogrammetric DSMs by intercomparison generally provides the basis for two different assumptions: (i) if the intervening changes of the reference surfaces between flights are negligible, it yields an empirical estimate of the internal precision of the UAS data acquisition and processing setup; (ii) in case real height changes of the snow surface (e.g., due to wind drift, snow fall, snow melt/settling) occur between two flights, it allows one to track the magnitude of these changes.

On all the campaign days, the AWS recorded air temperatures below $5{ }^{\circ} \mathrm{C}$, snow temperatures below

Table 4

Overview of UAS campaigns, details of data acquisitions (columns one through three), camera settings and output ('imagery' columns), (pre-) processing results as reported in PhotoScan ('photogrammetric processing' columns) (Adams et al. 2016)

\begin{tabular}{|c|c|c|c|c|c|c|c|c|c|c|c|}
\hline \multirow[t]{2}{*}{ Date } & \multirow[t]{2}{*}{ Time } & \multirow{2}{*}{$\begin{array}{l}\text { Campaign/ } \\
\text { flight number }\end{array}$} & \multicolumn{5}{|l|}{ Imagery } & \multicolumn{4}{|c|}{ Photogrammetric processing } \\
\hline & & & Sensor & \#Photos & Aperture & Exposure & ISO & $\begin{array}{l}\text { Mean } \\
\text { QI }\end{array}$ & Overlap & $\begin{array}{l}\text { Marker error } \\
(\mathrm{XYZ})[\mathrm{m}]\end{array}$ & $\begin{array}{l}\text { Reprojection error } \\
\text { (RMS/max.) [m] }\end{array}$ \\
\hline \multirow[t]{3}{*}{11.02 .2015} & 11:00 & $1 / 1$ & NIR830 & 1064 & $f / 4.5-8$ & $1 / 320$ & 100 & 0 & 10 & 0.14 & $0.2 / 4.3$ \\
\hline & $12: 00$ & $1 / 2$ & $\mathrm{VIS}^{\mathrm{a}}$ & 527 & f/10-18 & $1 / 320$ & 100 & 0.62 & 9 & 0.09 & $0.3 / 1.7$ \\
\hline & $13: 00$ & $1 / 3$ & $\mathrm{VIS}^{\mathrm{a}}$ & 897 & $\mathrm{f} / 8-18$ & $1 / 400$ & 100 & 0.52 & 11 & 0.08 & $0.3 / 1.4$ \\
\hline \multirow[t]{4}{*}{13.02 .2015} & $10: 30$ & $2 / 1$ & VIS & 884 & $\mathrm{f} / 7.1-14$ & $1 / 500$ & 100 & 0.57 & 16 & 0.08 & $0.3 / 1.4$ \\
\hline & $13: 30$ & $2 / 2$ & NIR830 & 973 & $\mathrm{f} / 4-9$ & $1 / 320$ & 100 & 0.72 & 6 & 0.22 & $0.9 / 3.7$ \\
\hline & $14: 00$ & $2 / 3$ & NIR700 & 863 & $\mathrm{f} / 4-16$ & $1 / 400$ & 100 & 0.66 & 10 & 0.1 & $0.3 / 4.2$ \\
\hline & $15: 00$ & $2 / 4$ & VIS & 680 & $\mathrm{f} / 5-18$ & $1 / 320$ & 100 & 0.65 & 4 & 0.03 & $0.3 / 1.4$ \\
\hline \multirow{2}{*}{03.03 .2015} & $10: 30$ & $3 / 1$ & VIS & 652 & $\mathrm{f} / 8-18$ & $1 / 500$ & 100 & 0.71 & 7 & 0.16 & $0.3 / 1.7$ \\
\hline & $13: 00$ & $3 / 2$ & NIR830 & 965 & $\mathrm{f} / 4-7.1$ & $1 / 500$ & 100 & 0.40 & 7 & 0.19 & $0.3 / 1.6$ \\
\hline \multirow[t]{3}{*}{13.03 .2015} & $13: 30$ & $4 / 1$ & VIS $^{\mathrm{a}}$ & 920 & $\mathrm{f} / 7.1-13$ & $1 / 500$ & 100 & 0.81 & 11 & 0.11 & $0.4 / 4.6$ \\
\hline & $14: 30$ & $4 / 2$ & $\mathrm{VIS}^{\mathrm{a}}$ & 500 & $\mathrm{f} / 4-11$ & $1 / 800$ & 100 & 0 & 7 & 0.2 & $0.3 / 1.2$ \\
\hline & $15: 30$ & $4 / 3$ & NIR830 & 544 & $\mathrm{f} / 2.5-14$ & $1 / 400$ & 400 & 0.88 & 9 & 0.12 & $0.5 / 1.9$ \\
\hline 21.08 .2015 & $13: 00$ & - & VIS & 1371 & $\mathrm{f} / 7.1$ & $\begin{array}{c}1 / 320-1 / \\
2000\end{array}$ & 400 & 0.81 & 36 & 0.4 & $0.4 / 2.8$ \\
\hline
\end{tabular}

${ }^{\mathrm{a}}$ Indicates data sets used for precision assessment in Sect. 2.3.2 
$-3{ }^{\circ} \mathrm{C}$, calm winds $\left(<3 \mathrm{~m} \mathrm{~s}^{-1}\right)$, no precipitation and a snow settling of less than $0.03 \mathrm{~m}$. We, therefore, follow assumption (i) in this paper when interpreting the precision assessment results. Precision of the UAS $\mathrm{UDMs}_{\mathrm{SD}}$ was determined following Fabris and Pesci (2005), by calculating $\Delta h_{i}$ residuals for each pixel of two UAS flights performed on the same day (Table 4). Standard deviation (SD) of the $\Delta h_{i}$ residuals distribution was reported as precision value. No separate precision calculations were performed for $\mathrm{UAS}_{\mathrm{DSMs}}$, as the reference 'snow-off' $\mathrm{UAS}_{\mathrm{DSM}}$ was the same for all the campaigns. We performed the assessment for:

i. A small area we considered to be the best-case scenario (snow heavily compacted, therefore, intermittent snow depth change was zero; highcontrast snow surface, therefore, high-point density expected in photogrammetric processing; planar surface with little elevation change, therefore, there is no influence of topography on the result).

ii. The whole AOI.

\section{Results and Discussion}

\subsection{Unmanned Aerial System}

Four 'snow-on' UAS campaigns were conducted between 11 February and 13 March 2015; details on data acquisition, camera settings and quality reports from photogrammetric (pre-) processing are presented in Table 4. 12 UAS flights were performed to record approximately 11,000 images in total, of which 9500 were used in photogrammetric image processing. Seven VIS, one NIR700 and four NIR830 data sets were acquired between 10.30 a.m. and 4 p.m. Each flight took approximately $35 \mathrm{~min}$. Camera settings were chosen according to the illumination conditions prior to UAS launch; priority was given to exposure (1/320-1/500), ISO was set at 100 for most flights, while aperture was adapted dynamically by the camera for each image (typically between $\mathrm{f} / 4$ and f/18).

Results from the QI calculation showed that twothirds of the UAS imagery have a satisfactory average QI above 0.62. Low average QI values were reported for imagery recorded on flights 1/3 (0.52), $2 / 1(0.57)$ and 3/2 (0.40); QI calculation failed for imagery from flights $1 / 1$ and $4 / 2(\mathrm{QI}=0)$ (Table 4). A visual check of the data sets confirmed a large amount of blurry imagery on flight $1 / 1$, possibly due to an error in data acquisition; no apparent deficiencies with regard to image sharpness were detected in the other imagery. As the calculation of the QI is poorly documented and therefore essentially black-box, no details on the impact of other deficiencies in UAS imagery are available. Therefore, the reason for the low QI of some UAS imagery is unknown. Overlap was at 'nine', indicating that, on average, each point within the AOI was visible in the nine UAS images. The lowest overlap was calculated for flight $2 / 2$, which, in turn, also features the highest marker $(0.22 \mathrm{~m})$ and reprojection error $(0.9 \mathrm{~m} / 3.7-\mathrm{RMS} /$ maximum error) of the 'snow-on' flights; all the marker errors reported in this section are mean values of all the seven RPs. The highest overlap by far (36) was achieved for the 'snow-off' UAS campaign. This was owed to the flight path design, which consisted of overcrossing flight lines parallel and orthogonal to the valley axis, as opposed to the winter flight lines, which were always orthogonal. The marker error for the summer reference flight was remarkably higher $(0.4 \mathrm{~m})$ than the average winter marker error $(0.13 \mathrm{~m})$. This may be due to the fact that the GNSS instrument used to survey the GCPs has a low accuracy (Sect. 2.2.1). Reprojection errors for all the data sets were below $0.4 \mathrm{~m}$ (RMSE) and below $1.9 \mathrm{~m}$ (maximum error). To calculate a statistically significant correlation between overlap, quality index and marker/reprojection error, the sample size $(n=13)$ is too small in the presented case; a visual interpretation of the results points to high overlap $(>8.9$, when excluding outlier 36) leading to low marker error $(<0.15 \mathrm{~m})$ and vice versa (valid for all flights except $2 / 4)$; little or no connection was found between the other parameters. This confirms results from previous studies, which have shown that high image overlap generally leads to a high signal-to-noise ratio in photogrammetric outputs and therefore low error at the GCPs (Zongjian et al. 2012; Haala 2011). This holds true especially when mapping low contrast surfaces, such as snow (Vander Jagt et al. 2015; 

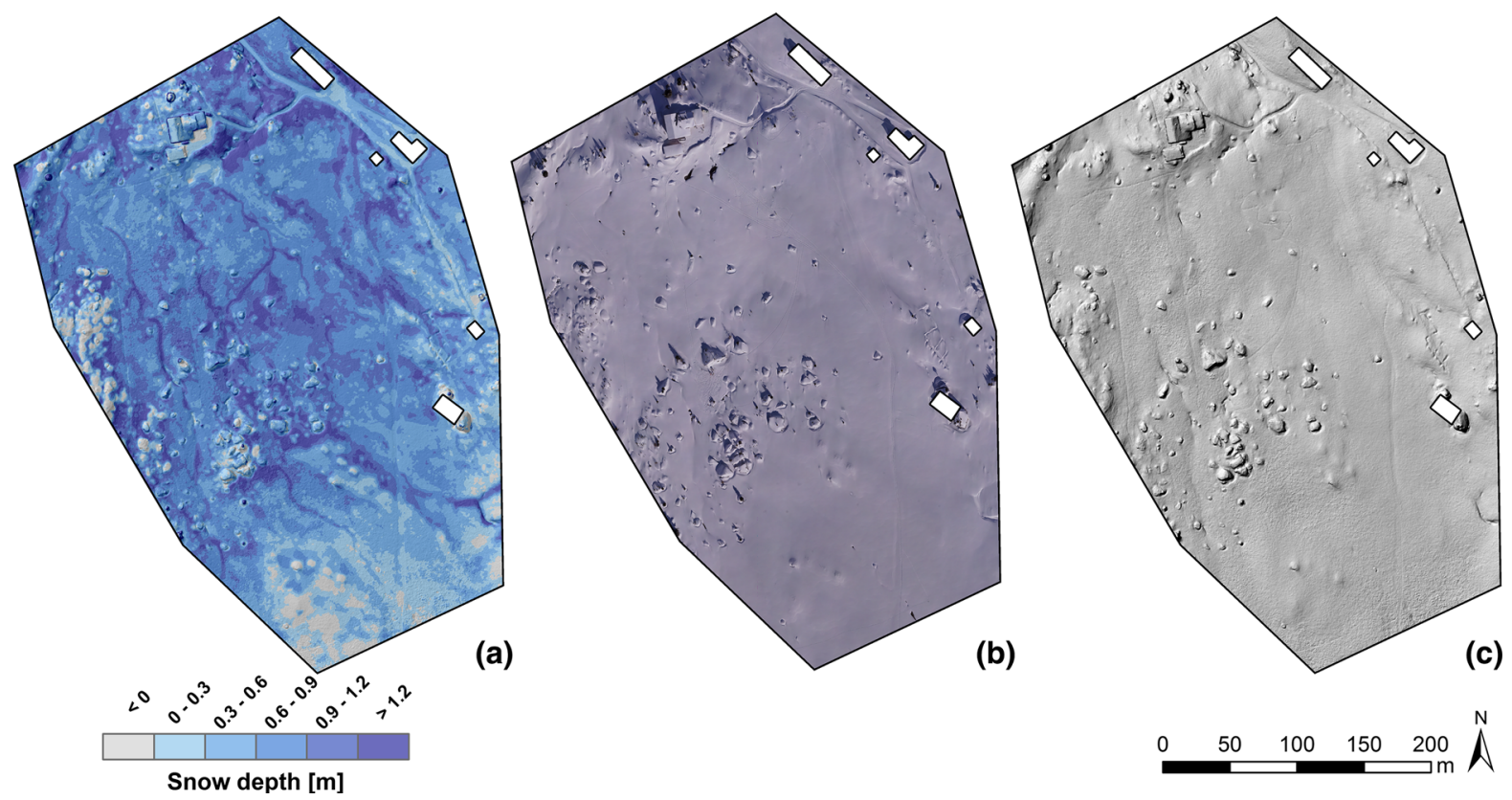

Figure 4

Results from photogrammetric processing of UAS imagery, generated on flight 3/1; SDM (a), orthophoto (b), hillshaded DSM (c)

Table 5

Details of collected TLS data (Adams et al. 2016)

\begin{tabular}{|c|c|c|c|c|c|c|c|c|c|c|}
\hline \multirow[t]{2}{*}{ Date } & \multicolumn{3}{|c|}{ Scanner settings } & \multicolumn{2}{|c|}{ Number of points } & \multicolumn{4}{|c|}{ Point distances $[\mathrm{m}]$} & \multirow[t]{2}{*}{ Standard deviation residues } \\
\hline & Instrument & Res. $X$ & Res. $Y$ & AOI & Filtered & Mean & Min. & Max. & $1 \sigma$ & \\
\hline 11.02 .2015 & LPM-321 & $0.063^{\circ}$ & $0.063^{\circ}$ & 271,511 & 171,983 & 0.13 & 0.001 & 5.46 & 0.10 & 0.07 \\
\hline 14.02 .2015 & LPM 98-2K & $0.054^{\circ}$ & $0.054^{\circ}$ & 268,155 & 183,064 & 0.16 & 0.001 & 8.77 & 0.12 & 0.11 \\
\hline 03.03 .2015 & LPM $98-2 \mathrm{~K}$ & $0.107^{\circ}$ & $0.108^{\circ}$ & 63,077 & 56,766 & 0.29 & 0.001 & 9.68 & 0.21 & 0.07 \\
\hline 11.03 .2015 & LPM 98-2K & $0.107^{\circ}$ & $0.108^{\circ}$ & 69,371 & 57,298 & 0.26 & 0.001 & 20.64 & 0.22 & 0.11 \\
\hline
\end{tabular}

Harder et al. 2016) or sand (Klemas 2015; Mancini et al. 2013).

In total, 12 'snow-on' and one 'snow off' orthophoto and DSM, as well as 12 SDMs for all the 'snow-on' flights were calculated. An example for an SDM (a), orthophoto (b) and hillshaded DSM (c) of flight 3/1, are shown in Fig. 4.

\subsection{Terrestrial Laser Scanning and Manual Snow Depth Probing}

Four TLS scans were selected for accuracy assessment of $\mathrm{UAS}_{\mathrm{DSMs}}$, based on their temporal proximity to UAS flights, quality and completeness.
One scan was performed with the LPM-321 (11 February 2015), three with the LPM 98-2K (14 February, 3 and 11 March 2015). The details of these scans are provided in Table 5. As described above, the number of measured TLS points (column 'AOI') was subsequently reduced to mitigate range bias (column 'Filtered'). In the section 'Point distances', descriptive statistics of the unfiltered point clouds are reported: The mean distance between points and consequently $1 \sigma$ is lowest for the LPM-321 measurement ( 0.13 and $0.1 \mathrm{~m}$, respectively). Average values for mean and $1 \sigma$ of point distances for all the campaigns are at 0.21 and $0.16 \mathrm{~m}$, respectively. Both measurements performed in March were recorded at 

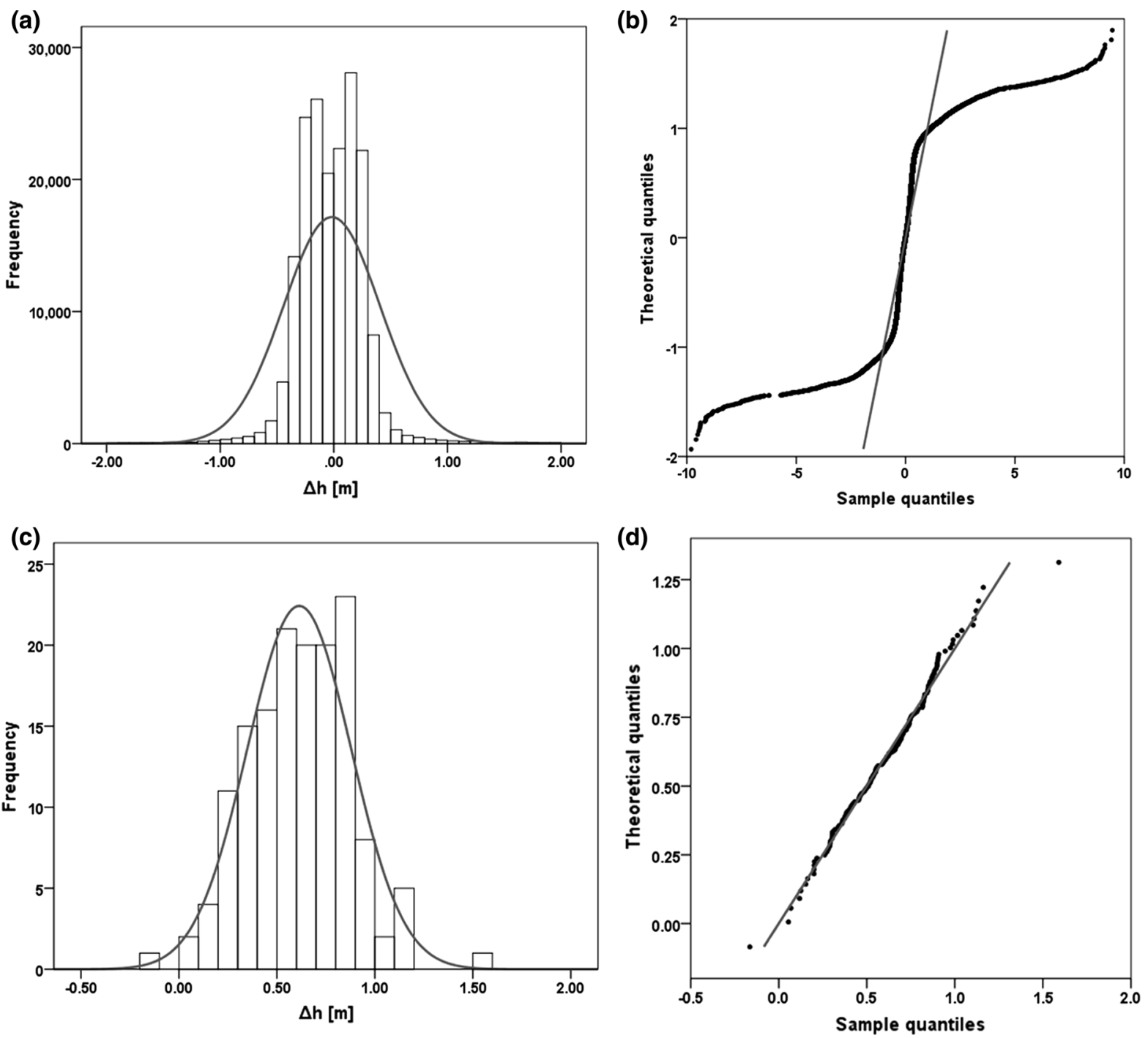

Figure 5

Visualisation of the error distributions of $\operatorname{UAS}_{\mathrm{DSMs}}(\mathbf{a}, \mathbf{b})$ and $\mathrm{UAS}_{\mathrm{SDMs}}(\mathbf{c}, \mathbf{d})$ for flight $2 / 1$; histograms $(\mathbf{a}, \mathbf{c})$ of $\Delta h_{i}$ in [m] with superimposed normal distribution, frequency corresponds to the number of measurements; Q-Q plots of $\Delta h_{i}$ (b, d) (Höhle and Höhle 2009)

lower resolution than the February data sets $\left(0.107^{\circ}\right.$ and $0.054^{\circ}$ azimuth resolution, respectively) and thus show larger point distances. Average geolocation residues (column 'Standard deviation residues') were $0.09 \mathrm{~m}$ and show no connection with the type of instrument used.

Results from the analysis of $\theta$ for the TLS measurements conducted on 11 February 2015 show a normal distribution around a median of $82^{\circ}$ $\left(1 \sigma=3.9^{\circ}\right)$. The corresponding $\delta$ values are leftskewed (skewness $=230$ ) and comparatively large $\left(\right.$ median $=0.47 \mathrm{~m}^{2}, \quad 68.3 \% \quad$ quantile $\left.=1.24 \mathrm{~m}^{2}\right)$, considering the close range $(<300 \mathrm{~m})$ and small beam divergence of the LPM-321 (typically $0.8 \mathrm{mrad})$. This confirms the assumption of an unfavourable measurement setup for TLS validation. An analysis of the spatial distribution of $\delta$ values shows that it is dominated by range. An analysis of the spatial distribution of $\delta$ values shows they are dominated by range, due to increasingly acute viewing angles $\left(r_{\mathrm{SP}}=0.94\right.$ between $\delta$ and $\left.\theta\right)$. By comparison, increasing divergence of the laser beam 
Table 6

Overview of statistical analysis of the $U A S_{D S M}$ and $U A S_{S D M}$ errors for all flights

\begin{tabular}{|c|c|c|c|c|c|c|c|c|c|c|c|c|}
\hline \multirow[t]{2}{*}{ Accuracy measure } & \multicolumn{12}{|c|}{ Campaign/flight number } \\
\hline & $1 / 1$ & $1 / 2$ & $1 / 3$ & $2 / 1$ & $2 / 2$ & $2 / 3$ & $2 / 4$ & $3 / 1$ & $3 / 2$ & $4 / 1$ & $4 / 2$ & $4 / 3$ \\
\hline \multicolumn{13}{|l|}{$\mathrm{UAS}_{\mathrm{DSM}}$ error } \\
\hline Skewness & -2 & -2 & -2 & 0 & 1 & -1 & -23 & 3 & 3 & 1 & 2 & 0 \\
\hline Kurtosis & 57 & 101 & 128 & 114 & 146 & 143 & 1842 & 123 & 108 & 108 & 74 & 34 \\
\hline Median & -0.20 & 0.17 & 0.10 & -0.02 & -0.06 & 0.09 & -0.19 & -0.08 & 0.09 & -0.12 & -0.19 & -0.34 \\
\hline NMAD & 0.32 & 0.27 & 0.17 & 0.28 & 0.16 & 0.15 & 0.43 & 0.12 & 0.14 & 0.17 & 0.28 & 0.51 \\
\hline $68.3 \%$ quantile & 0.41 & 0.34 & 0.23 & 0.25 & 0.19 & 0.19 & 0.49 & 0.19 & 0.21 & 0.26 & 0.35 & 0.55 \\
\hline $95 \%$ quantile & 0.96 & 0.57 & 0.55 & 0.52 & 0.47 & 0.45 & 1.33 & 0.63 & 0.50 & 0.69 & 0.81 & 1.70 \\
\hline \multicolumn{13}{|l|}{$\mathrm{UAS}_{\mathrm{SDM}}$ error } \\
\hline Skewness & 0 & -1 & 0 & 0 & -1 & 0 & 0 & - & - & - & - & - \\
\hline Kurtosis & 0 & 0 & 2 & 0 & 1 & 1 & 0 & - & - & - & - & - \\
\hline Median & -0.29 & -0.06 & -0.07 & -0.24 & -0.21 & -0.15 & -0.30 & - & - & - & - & - \\
\hline SD & 0.36 & 0.26 & 0.21 & 0.21 & 0.14 & 0.19 & 0.35 & - & - & - & - & - \\
\hline $\mathrm{ME}^{\mathrm{a}}$ & -0.16 & 0.10 & 0.13 & -0.03 & -0.03 & 0.01 & -0.12 & - & - & - & - & - \\
\hline $\mathrm{MAE}^{\mathrm{a}}$ & 0.29 & 0.23 & 0.20 & 0.18 & 0.11 & 0.15 & 0.29 & - & - & - & - & - \\
\hline RMSE $^{\mathrm{a}}$ & 0.39 & 0.28 & 0.26 & 0.22 & 0.14 & 0.19 & 0.37 & - & - & - & - & - \\
\hline
\end{tabular}

${ }^{\mathrm{a}}$ Calculated without offset (Sect. 3.3.3)

with range (diameter increases by $0.24 \mathrm{~m}$ between 0 and $300 \mathrm{~m}$ ), or local variations of the terrain slope angle have less influence on the result $\left(r_{\mathrm{SP}}=-0.3\right.$ between $\delta$ and slope angle). We also checked correlation between $\delta$ and TLS error values for all the flights and found none $\left(r_{\mathrm{SP}}\right.$ between -0.07 and 0.04). To sum up, although the calculated $\delta$ values are relatively large, compared to the size of the $\mathrm{UAS}_{\mathrm{DSM}}$ pixels, $\delta$ is independent from the magnitude of error in the $\mathrm{UAS}_{\mathrm{DSMs}}$.

149 MP checkpoints were measured in the late afternoon of 11 February 2015. The grid pattern of the data collection routine had an average spacing of $18 \mathrm{~m}$. Average snow depth was $0.83 \mathrm{~m}$, with a maximum of $1.4 \mathrm{~m}$. Snow depth differences within the $2 \times 2 \mathrm{~m}$ plots at each checkpoint were as high as $0.8 \mathrm{~m}$, with an average of $0.23 \mathrm{~m}$.

\subsection{Accuracy and Precision Assessment}

\subsubsection{Error Distribution}

The histograms and Q-Q plots showed that distributions of $\mathrm{UAS}_{\mathrm{DSM}}$ and $\mathrm{UAS}_{\mathrm{SDM}}$ error followed a characteristic pattern. Examples of each type of distribution and plot are shown in Fig. 5.
The $\mathrm{UAS}_{\mathrm{DSM}}$ error distributions (Fig. 5a, b), show a high amount of values around the median $( \pm 0.5 \mathrm{~m})$ and clear deviation from the superimposed normal distribution in the histogram. The Q-Q plot confirms the impression of a non-normal error distribution; the deviation of the plotted values from the straight line indicates a large amount of outliers and therefore heavy tails of the error distribution (Höhle and Höhle 2009). These observations agree with the general notion that non-normal error distribution is very common in photogrammetric DSMs, as stated in textbooks and related studies (e.g., Müller et al. 2014; Maune 2007). The $\mathrm{UAS}_{\mathrm{SDM}}$ error distribution, on the other hand (Fig. 5c, d), shows good agreement with the normal distribution in the histogram. This observation is confirmed in the Q-Q plot; the plotted values are mostly located close to the line, indicating close resemblance between the empirical quantiles distribution and the theoretical quantiles of a normal distribution (Höhle and Höhle 2009). Skewness and kurtosis are shown in Table 6; skewness remains within \pm 3 (except for flight 2/4) for $\mathrm{UAS}_{\mathrm{DSM}}$ and $\mathrm{UAS}_{\mathrm{SDM}}$ errors; however, kurtosis is high for $\mathrm{UAS}_{\mathrm{DSM}}$ errors (mean $=100$, if excluding the outlier flight $2 / 4$ ) and very low (mean $=0.6$ ) in the $\mathrm{UAS}_{\mathrm{SDM}}$ errors (also apparent in histograms Fig. 5a, c). The general difference in error 

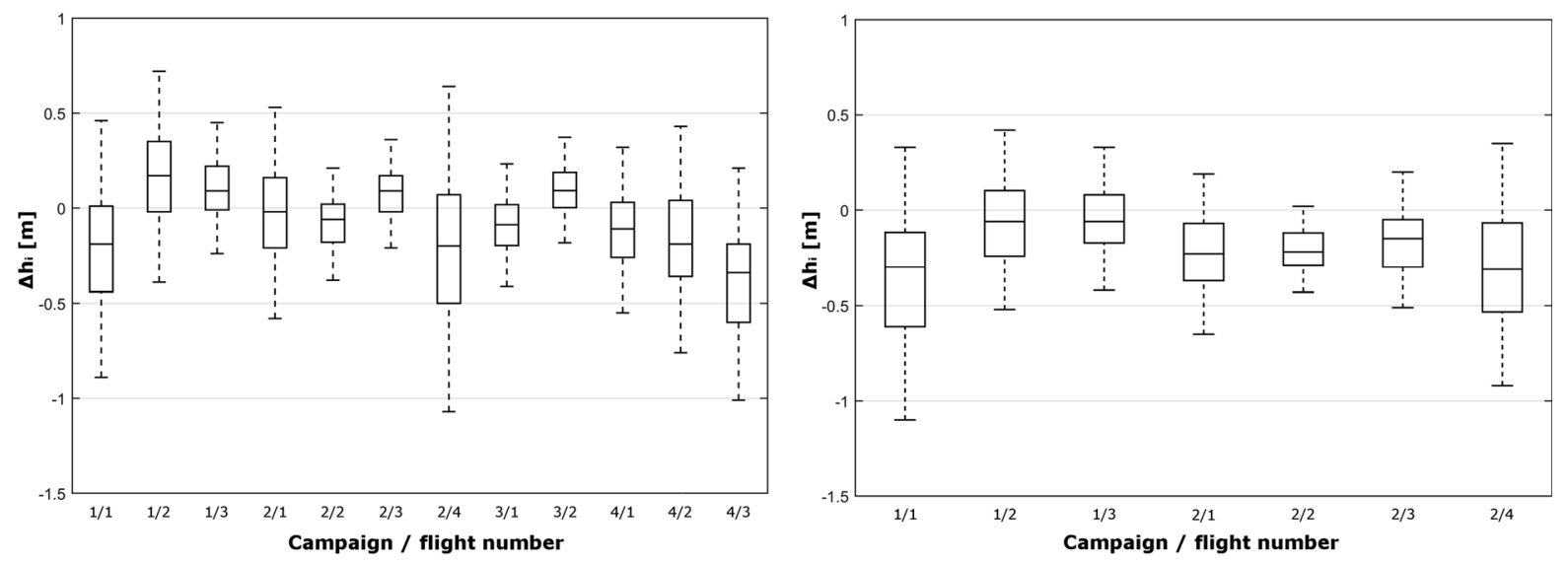

Figure 6

Boxplots of $\mathrm{UAS}_{\mathrm{DSM}}$ error (left image) and $\mathrm{UAS}_{\mathrm{SDM}}$ error (right image); $y$-axis shows $\Delta h_{i}[\mathrm{~m}]$, ID of UAS flight (campaign/flight number) are plotted on $x$-axis; whiskers in boxplot correspond to $1 \sigma$, outliers not shown; boxplots truncated at $1 /-1.5 \mathrm{~m}$ for better visualisation

distributions and kurtosis values between $\mathrm{UAS}_{\mathrm{DSM}}$ and $\mathrm{UAS}_{\mathrm{SDM}}$ could be explained by the fact, that the majority of outliers in laser scanning and photogrammetric DSMs are caused by objects with high vertical offset from the terrain (Höhle and Höhle 2009). In the presented case, the TLS surveys the height of the snow surface and objects with high vertical offset (i.e., buildings, boulders, trees), thus potentially generating outliers (and therefore high kurtosis values); the MP routine, however, only samples the snow surface, therefore the accuracy assessment of $\mathrm{UAS}_{\mathrm{SDM}}$ is less prone to outliers and shows very low kurtosis values. Based on these observations, a normal distribution is assumed for the $\mathrm{UAS}_{\mathrm{SDM}}$ errors, and a non-normal distribution for the $\mathrm{UAS}_{\mathrm{DSM}}$ errors.

\subsubsection{Accuracy Assessment of $U A S_{D S M}$}

Results of the $\mathrm{UAS}_{\mathrm{DSM}}$ accuracy assessment are provided in Table 6 and visualised in boxplots (Fig. 6). The results show a high error variability between the UAS flights. Low values for NMAD $(<0.2 \mathrm{~m}), 68.3 \%$ quantile $(<0.25 \mathrm{~m})$ and $95 \%$ quantile $(<0.55 \mathrm{~m})$ were determined for approximately half the flights (e.g. $1 / 3,2 / 2$ or $3 / 2$ ). This translates to 68.3 and $95 \%$ of the $\mathrm{UAS}_{\mathrm{DSM}}$ errors of these flights being within a magnitude of \pm 0.25 and $\pm 0.55 \mathrm{~m}$, respectively (Höhle and Höhle 2009). The assessment of at least three flights (i.e., 1/1, 2/4 and 4/3), however, shows comparatively high values for the above-mentioned robust accuracy measures ( $>0.3,>0.4$ and $\geq 1 \mathrm{~m}$, respectively). The error medians are all within $\pm 0.2 \mathrm{~m}$ (except for flight 4/3). We analysed the correlation between indicators from the photogrammetric processing report (i.e., QI, overlap, marker error and reprojection error) and results from the $\mathrm{UAS}_{\mathrm{DSM}}$ accuracy assessment (i.e., median, NMAD, 68.3 and $95 \%$ quantiles). The highest correlations were found between marker error and NMAD $(r=-0.39)$, and marker error and $68.3 \%$ quantile $(r=-0.35)$; all the other pairings were $r<0.3$. It therefore seems that from a statistical view-point, the photogrammetric processing indicators have little explanatory power regarding the accuracy of the UAS $\mathrm{DSM}_{\mathrm{DS}}$ when assessed with TLS. This could either be due to the fact that the chosen indicators are not statistically significant, or that the chosen sample size is too small to correctly show correlation between these indicators.

Exemplary results of the spatial distribution of errors from flights $1 / 1$ through $1 / 3$ are provided in Fig. 7. They show that the high (mostly negative) $\mathrm{DSM}_{\mathrm{UAS}}$ errors of flight $1 / 1$ reported in Table 6 occur mainly in the east (near the TLS instrument) and far west of the AOI (close to a large boulder and stone pine cluster-inset in Fig. 1). The $\mathrm{UAS}_{\mathrm{DSM}}$ errors of flight $1 / 2$ are mostly positive and are located in the AOI centre. While the overall error in $\mathrm{UAS}_{\mathrm{DSM}}$ of flight $1 / 3$ is low (i.e., $68.3 \%$ quantile $=0.23 \mathrm{~m}$, most 

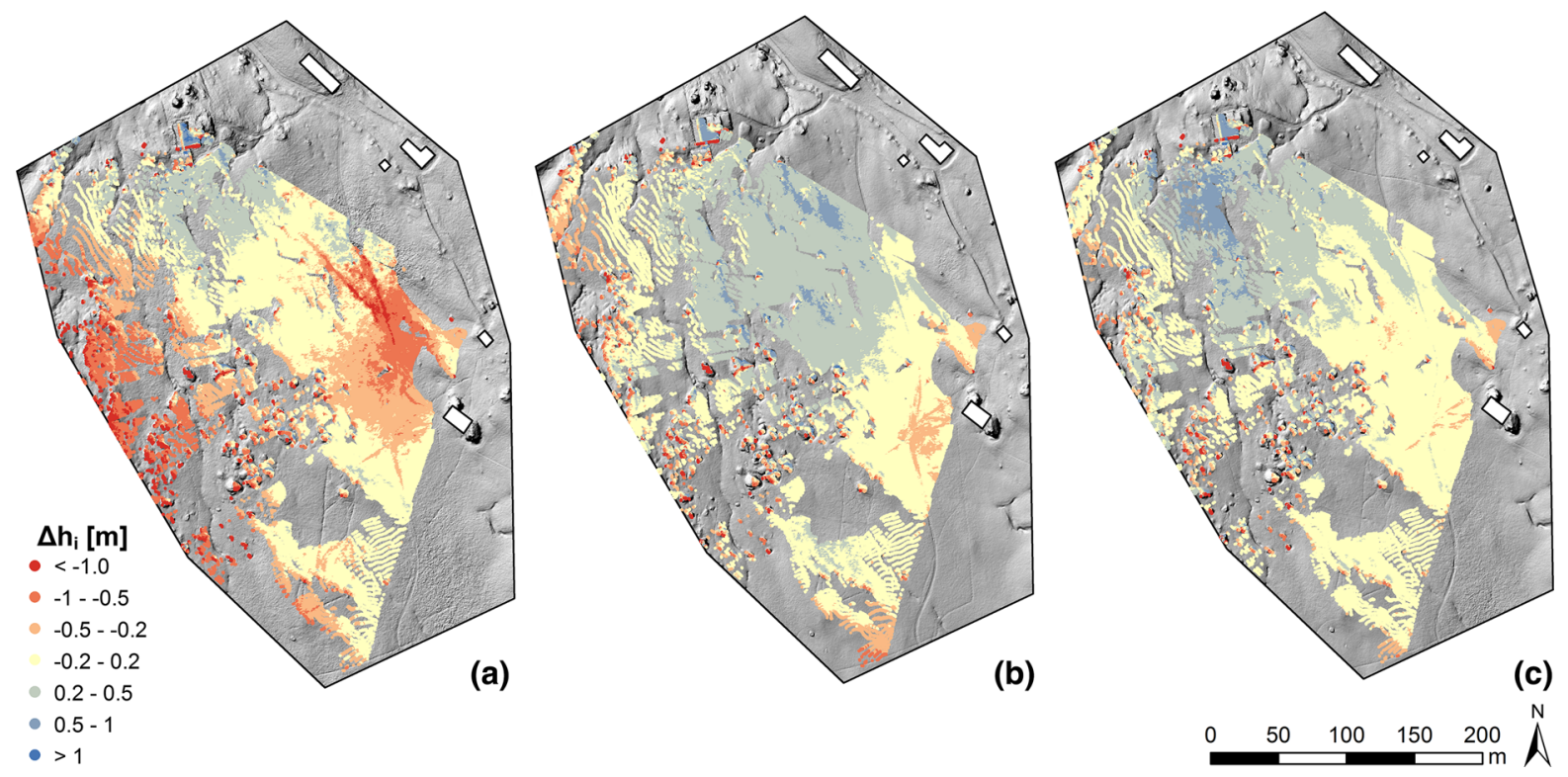

Figure 7

Results from accuracy assessment of $\mathrm{UAS}_{\mathrm{DSM}}$ recorded on 11 February 2015 [flights 1/1 (a), 1/2 (b) and 1/3 (c)]; reds indicate negative, blues positive $\Delta h_{i}$ values (Adams et al. 2016)

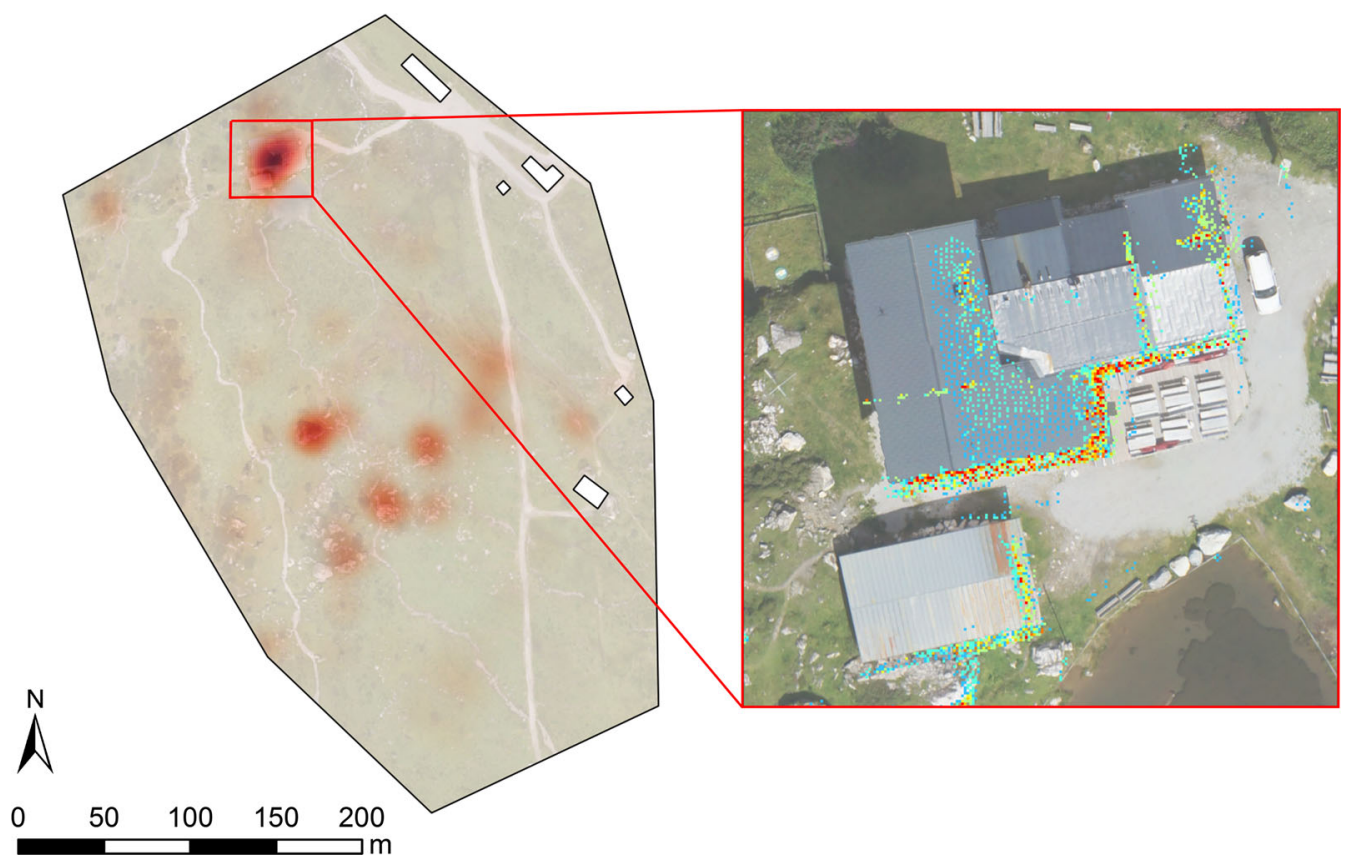

Figure 8

Location and occurrence of outliers; outlier heatmap of AOI-the darker the red, the more outliers in this area (left image); number of outlier occurrences at largest hotspot (red rectangle), coloured blue $=2$ through red $=7$ or more, per $0.2 \mathrm{~m}$ grid cell (right image); UAS orthophoto from 21 August 2015 in background of both figures 
plotted checkpoints within $\pm 0.2 \mathrm{~m}$ ), an area of approximately $0.002 \mathrm{~km}^{2}$ in the central part of the AOI shows high errors $(0.5-1 \mathrm{~m})$, surrounded by a $0.012 \mathrm{~km}^{2}$ large area with errors in the $0.2-0.5 \mathrm{~m}$ range. Additionally, outliers were identified (i.e., errors outside the above-mentioned $95 \%$ quantile) and their location mapped for all the UAS flights. They mainly occur in the central and northern area of the AOI (Fig. 8, left image). Additionally, the number of outlier occurrences was counted in each $0.2 \mathrm{~m}$ grid cell (equivalent to $\mathrm{UAS}_{\mathrm{DSM}}$ cell size); high values are predominant on steep rock faces of large boulders (central AOI section, not shown) and the façades of buildings (Fig. 8, right image). A small amount of pixels $(n=46)$ within these areas were classified as outliers on all the flights. This further confirms the observations described in Sect. 3.3.1. Generally, the magnitude of error is complimentary in both statistical and spatial representations. However, the latter allows a more goal-oriented analysis of factors influencing $\mathrm{UAS}_{\mathrm{DSM}} / \mathrm{UAS}_{\mathrm{SDM}}$ error. An example was presented in a related publication, the potential of using NIR sensors to collect UAS imagery under very poor illumination conditions and its impact on the accuracy of $\mathrm{UAS}_{\mathrm{DSMs}} / \mathrm{UAS}_{\mathrm{SDMs}}$ (Bühler et al. 2017).

\subsubsection{Accuracy Assessment of $U A S_{S D M s}$}

Results of the $\mathrm{UAS}_{\mathrm{SDM}}$ error analysis are also included in Table 6 and Fig. 6 (boxplots-right image). The error median and five out of seven upper quantiles are below zero, indicating a systematic offset between both the data sets: snow depth values mapped with the UAS were generally lower than snow depth values measured with MP. The average of this offset was $-0.19 \mathrm{~m}$. As described in detail in related publications (Adams et al. 2016; Bühler et al. 2016), these irregularities are caused by the interaction of vegetation with the snow cover. To exclude systematic error from the subsequent calculation of accuracy measures, mean, MAE and RMSE were determined after subtracting the offset from the measured values (Table 6). Compared to the $\mathrm{UAS}_{\mathrm{DSM}}$ errors described above, the boxplots show a lower spread of the $\mathrm{UAS}_{\mathrm{SDM}}$ errors. The $\mathrm{UAS}_{\mathrm{SDM}}$ RMSE of the middle five UAS flights (1/2 through
$2 / 3$ ) is $\leq 0.28 \mathrm{~m}$, while flights $1 / 1$ and $2 / 4$ show a higher RMSE $(>0.37 \mathrm{~m})$. The same holds true for the reported MAE $(\leq 0.23$ and $>0.29 \mathrm{~m}$, respectively) and $\mathrm{SD}(\leq 0.26$ and $>0.35 \mathrm{~m}$, respectively) (Fig. 6-right image). As with the $\mathrm{UAS}_{\mathrm{DSM}}$ errors, we analysed the correlation between $\mathrm{UAS}_{\mathrm{SDM}}$ accuracy measures and indicators reported during photogrammetric processing; the highest $r$ values were found for QI - SD $(r=-0.65)$, RMS reprojection error $-\mathrm{SD}(r=-0.64)$, RMS reprojection error - MAE $\quad(r=-0.68), \quad$ QI - RMSE $(r=-0.67)$ and RMS reprojection error - RMSE ( $r=-0.65$ ); all the other pairings were $r<0.6$. Although, in absolute terms, these correlations are again not very strong, they indicate that a higher QI and/or lower RMS reprojection error may result in an overall higher accuracy of the $\mathrm{UAS}_{\mathrm{SDM}}$.

\subsubsection{Precision}

As highlighted in related publications concerning UAS-based snow depth mapping (Bühler et al. 2016, 2017), illumination of the snow surface, sensor choice and the presence of minor disturbances of the snow surface (e.g., due to ski tracks) have a large impact on structure-from-motion image matching and therefore on the accuracy and precision of $\mathrm{UAS}_{\mathrm{DSMs}}$ and $\mathrm{UAS}_{\text {SDMs. }}$. Thus, only data collected under similar illumination conditions with the same VIS sensor setup from the same day (minimal disturbance of the snowpack by MP measurements) were considered in this precision assessment (Table 5). None of the available NIR data fitted these criteria; therefore, the precision assessment was limited to VIS data. A comparison of flights $1 / 2$ versus $1 / 3$ and $4 / 1$ versus 4/2 for precision assessment is presented in Fig. 9. The profile plot shows snow depth values for four $\mathrm{UAS}_{\text {SDMs }}$ mapped along a $90 \mathrm{~m}$ stretch of cleared road (transect A-B). In three of the four $\mathrm{UAS}_{\mathrm{SDMs}}$ in Fig. 9, negative snow depth values occur (grey patches), especially in the flight $1 / 3$ profile plot. This can be explained by the very shallow snow depths along the cleared road (Sect. 2.3.2) and the slightly negative bias of the $\mathrm{UAS}_{\mathrm{SDM}}$ error (Fig. 6, Sect. 3.3.3). As described above, the precision is reported as the SD of the residues between both the acquisitions. For the profile line in Fig. 9 this was $0.04 \mathrm{~m}$ for 


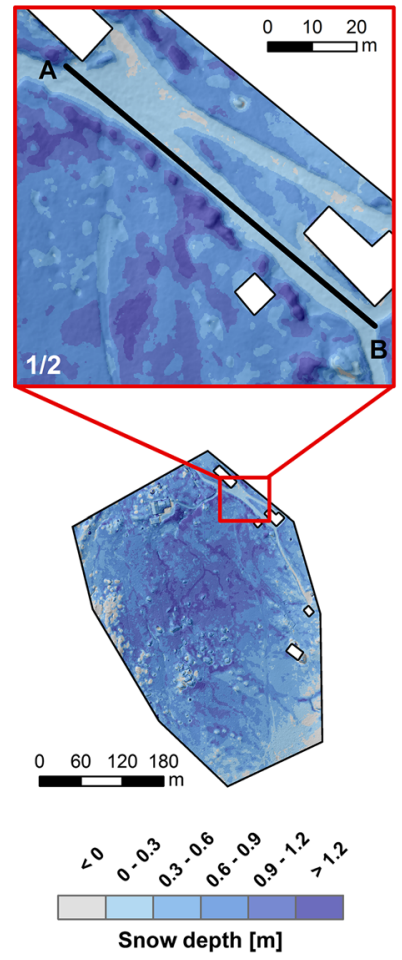

(a)
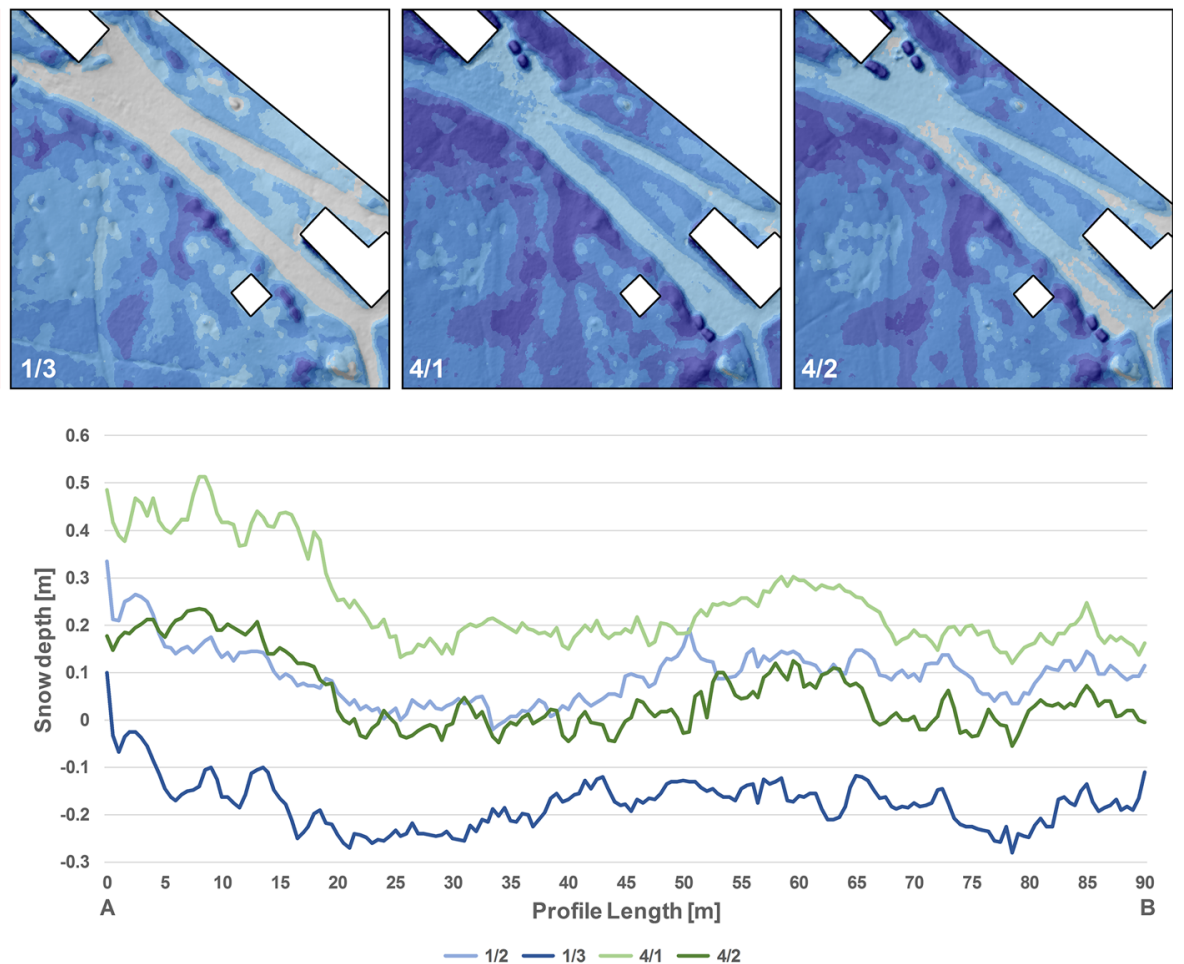

(b)

Figure 9

Precision assessment of $\mathrm{UAS}_{\mathrm{SDMs}}$; overview AOI snow depth values for flight 1/2 (a); detail-view of area marked with red rectangle for flights $1 / 2,1 / 3,4 / 1$ and 4/2 (top row); snow depth values along profile (A-B) for all flights (b)

the comparison between both flights. For the entire AOI (approximately 6 million pixels), analysis of the residuals showed they were non-normally distributed; following the procedure applied to the accuracy assessment above, the 68.3 and $95 \%$ quantiles are reported: 0.25 and $0.55 \mathrm{~m}$ for 11 February, 0.33 and $0.99 \mathrm{~m}$ for $13 \mathrm{March}$, respectively.

\subsection{Comparable Studies}

To relate these results to the existing literature, Table 7 provides an overview of recent, comparable studies, dealing with accuracy assessment of UAS photogrammetry for snow depth mapping. A direct relation of findings from the presented study with comparable studies is limited, because:

i. Most studies are based on one to three UAS winter flights (all except Harder et al. 2016), thus temporal accuracy change cannot be investigated. ii. Different kinds of reference data, with varying nominal accuracies were used.

iii. The employed methodologies for data processing and error analysis varied considerably and different accuracy measures were reported.

iv. The size and topography of the AOI varied considerably $\left(0.007-0.65 \mathrm{~km}^{2}\right.$; steep mountain slopes vs. flat areas), incurring size- and terraineffects on the results.

When putting aside these difficulties, it seems the accuracy reported here is within a similar range to the related studies. However, especially the implementation of recently available high-accuracy geolocation routines (e.g., real time kinematic GNSS) is able to substantially increase accuracy (Harder et al. 2016).

Of the studies presented in Table 7, only four reports on the precision of $\mathrm{UAS}_{\mathrm{DSMs}} / \mathrm{UAS}_{\mathrm{SDMs}}$ : De Michele et al. (2016), Lendzioch et al. (2016) and Vander Jagt et al. (2015) report precision as the SD of 
Table 7

Overview of results from accuracy assessments in comparable studies for UAS-based snow depth mapping; geolocation errors reported in some listed studies are not included in this overview; multiple rows per study correspond to different sites and/or different reference measurements and related results

\begin{tabular}{|c|c|c|c|c|c|c|c|}
\hline Author(s) & $\begin{array}{l}\text { Size of } \\
\text { AOI } \\
{\left[\mathrm{km}^{2}\right]}\end{array}$ & $\begin{array}{l}\text { \# UAS } \\
\text { flights } \\
\text { (winter) }\end{array}$ & UAS type & Sensor(s) & $\begin{array}{l}\text { Reference } \\
\text { measurement(s) }\end{array}$ & $\begin{array}{l}\text { Evaluated } \\
\text { parameters }\end{array}$ & Results \\
\hline $\begin{array}{l}\text { Avanzi et al. } \\
\text { (2017) }\end{array}$ & 0.007 & 1 & Multicopter & RGB & $\begin{array}{l}\text { Multistation } \\
\text { MP }\end{array}$ & $\begin{array}{l}\text { DSM/point } \\
\text { cloud } \\
\quad(z \text { values }) \\
\text { Snow depth } \\
\quad(z \text { values })\end{array}$ & $\begin{array}{l}\mathrm{SD}=0.056 / 0.025 \mathrm{~m} ; \\
\mathrm{RMSE}=0.069 / 0.036 \mathrm{~m} \\
\mathrm{SD}=0.14-0.27 \mathrm{~m} \\
\mathrm{RMSE}=0.17-0.45 \mathrm{~m}\end{array}$ \\
\hline $\begin{array}{l}\text { Boesch et al. } \\
\text { (2016) }\end{array}$ & 0.35 & 2 & Multicopter & $\begin{array}{c}\text { RGB \& } \\
\text { NIR }\end{array}$ & $\begin{array}{l}\text { ADS } 100^{\mathrm{b}} \\
\text { GNSS }\end{array}$ & $\begin{array}{l}\text { DSM } \\
\quad(z \text { values })\end{array}$ & $\begin{array}{l}\text { Median }=0.06-0.08 \mathrm{~m} \\
\text { Median }=0.1-0.17 \mathrm{~m}\end{array}$ \\
\hline $\begin{array}{l}\text { De Michele et al. } \\
\text { (2016) }\end{array}$ & 0.03 & 1 & Fixed-wing & RGB & MP & $\begin{array}{r}\text { Snow depth } \\
\text { ( } z \text { values })\end{array}$ & $\mathrm{SD}=0.13 \mathrm{~m} ; \mathrm{RMSE}=0.14 \mathrm{~m}$ \\
\hline $\begin{array}{l}\text { Harder et al. } \\
\qquad(2016)\end{array}$ & $\begin{array}{l}0.65 \text { (site } \\
\text { A) } \\
0.32 \text { (site } \\
\text { B) }\end{array}$ & $\begin{array}{l}22 \\
18\end{array}$ & Fixed-wing & RGB & GNSS & $\begin{array}{l}\text { DSM } \\
\quad(z \text { values })\end{array}$ & $\begin{array}{l}\mathrm{SD}=0.06-0.08 \mathrm{~m} \\
\mathrm{RMSE}=0.08-0.012 \mathrm{~m} \\
\mathrm{SD}=0.05-0.06 \mathrm{~m} \\
\mathrm{RMSE}=0.08-0.09 \mathrm{~m}\end{array}$ \\
\hline $\begin{array}{l}\text { Lendzioch et al. } \\
\text { (2016) }\end{array}$ & $\begin{array}{l}0.26^{\mathrm{c}} \\
\quad(\text { site A) } \\
0.005 \\
\quad(\text { site B) }\end{array}$ & 2 & Multicopter & RGB & MP & $\begin{array}{r}\text { Snow depth } \\
(z \text { values })\end{array}$ & $\begin{array}{l}\mathrm{SD}=0.22 \mathrm{~m} ; \mathrm{RMSE}=0.22 \mathrm{~m} \\
\mathrm{SD}=0.36 \mathrm{~m} ; \mathrm{RMSE}=0.42 \mathrm{~m}\end{array}$ \\
\hline $\begin{array}{l}\text { Marti et al. } \\
\text { (2016) }\end{array}$ & 0.31 & 1 & Fixed-wing & RGB & $\begin{array}{l}\text { Pléiades }^{\mathrm{d}} \\
\text { GNSS }\end{array}$ & $\begin{array}{r}\text { Snow depth } \\
(z \text { values })\end{array}$ & $\begin{array}{l}\mathrm{SD}=1.47 \mathrm{~m} ; \mathrm{NMAD}=0.78 \mathrm{~m} \\
\mathrm{SD}<0.63 \mathrm{~m} ; \mathrm{NMAD}<0.38 \mathrm{~m}\end{array}$ \\
\hline $\begin{array}{l}\text { Miziński and } \\
\text { Niedzielski } \\
\text { (2017) }\end{array}$ & 0.04 & 2 & Fixed-wing & $\begin{array}{l}\text { RGB and } \\
\text { NIR }\end{array}$ & MP & $\begin{array}{r}\text { Snow depth } \\
(z \text { values })\end{array}$ & $\begin{array}{l}\mathrm{MAE}=0.33-0.43 \mathrm{~m} ; \\
\mathrm{RMSE}=0.41-0.58 \mathrm{~m} \\
\mathrm{NMAD}=0.37-0.55 \mathrm{~m}\end{array}$ \\
\hline $\begin{array}{l}\text { Vander Jagt et al. } \\
\text { (2015) }\end{array}$ & 0.007 & 1 & Multicopter & RGB & GNSS & $\begin{array}{r}\text { Snow depth } \\
(z \text { values })\end{array}$ & $\mathrm{RMSE}=0.9 \mathrm{~m}$ \\
\hline $\begin{array}{l}\text { Bühler et al. } \\
\qquad(2016)^{\mathrm{e}}\end{array}$ & $\begin{array}{l}0.12 \text { (site } \\
\text { A) } \\
0.35 \text { (site } \\
\text { B) }\end{array}$ & $\begin{array}{l}1 \\
3\end{array}$ & Multicopter & $\begin{array}{l}\text { RGB and } \\
\text { NIR }\end{array}$ & MP & $\begin{array}{r}\text { Snow depth } \\
(z \text { values })\end{array}$ & $\begin{array}{l}\mathrm{RMSE}=0.07-0.3 \mathrm{~m} \\
\mathrm{RMSE}=0.15 \mathrm{~m}\end{array}$ \\
\hline $\begin{array}{l}\text { Bühler et al. } \\
(2017)^{\mathrm{e}}\end{array}$ & $\begin{array}{l}0.12 \text { (site } \\
\text { A) } \\
0.12 \text { (site } \\
\text { B) }\end{array}$ & $\begin{array}{l}3 \\
4\end{array}$ & $\begin{array}{l}\text { Multicopter } \\
\text { Fixed-wing }\end{array}$ & $\begin{array}{l}\text { RGB and } \\
\text { NIR }\end{array}$ & $\begin{array}{l}\text { GNSS } \\
\text { TLS }\end{array}$ & $\begin{array}{l}\text { DSM } \\
\quad(z \text { values })\end{array}$ & $\begin{array}{l}\mathrm{SD}=0.11-0.19 \mathrm{~m} ; \\
\mathrm{RMSE}=0.17-0.23 \mathrm{~m} \\
\mathrm{RMSE}=0.18-0.77 \mathrm{~m}\end{array}$ \\
\hline
\end{tabular}

${ }^{\mathrm{a}}$ Data collected in scanning mode

${ }^{\mathrm{b}}$ Large-frame aerial camera on-board manned aircraft

${ }^{\mathrm{c}}$ Total size of area - AOI-size not provided

${ }^{\mathrm{d}}$ Very high resolution satellite imagery (two imagery triplets with $0.7 \mathrm{~m}$ ground sampling distance used to generate 1,2 and $4 \mathrm{~m}$ DSMs)

${ }^{\text {e}}$ Studies also published within the project RPAS4SNOW

$\mathrm{UAS}_{\mathrm{SDM}}$ values of a single flight $(0.1,0.22-0.45$, $0.21 \mathrm{~m}$, respectively); Bühler et al. (2016) determined the precision by calculating the $\mathrm{SD}$ of residues for several UAS acquisitions along a limited, stable area $(\mathrm{SD}<0.1 \mathrm{~m})$, similar to the method used here. Precision results from the presented study are, therefore, in a similar range as in comparable studies, both with regard to small, stable areas and area-wide estimates.

\section{Conclusions}

In this work, we present a multitemporal assessment of the accuracy and precision of fixed-wing UAS photogrammetry for slope-scale snow depth mapping in alpine terrain. VIS and NIR imagery was collected with a modified off-the-shelf digital camera, mounted on a custom-built fixed-wing UAS. We 
performed 12 UAS flights during four campaigns in February and March 2015 in 'snow-on' and one in August 2015 in 'snow-off' conditions. The data were collected at a flat $0.12 \mathrm{~km}^{2}$ study site, located at approximately $2000 \mathrm{~m}$ a.s.l. While all the UAS imagery was processed with the same parameter settings in structure-from-motion photogrammetry software, it was collected under different site- and UAS-specific settings. This allowed testing the setup under different conditions and investigating factors influencing the quality of the UAS $\mathrm{USMs}_{\mathrm{s}}$ and $\mathrm{UAS}_{\text {SDMs. }}$. Our assessment followed a threefold approach:

1. Accuracy assessment of $\mathrm{UAS}_{\mathrm{DSMs}}$ with TLS reference data.

2. Accuracy assessment of $\mathrm{UAS}_{\mathrm{SDMs}}$ with MP reference data.

3. Precision assessment of $\mathrm{UAS}_{\mathrm{SDMs}}$ by intercomparison of multiple UAS results.

Ad (1) To determine how well UAS photogrammetry was able to map the absolute height of the snow surface, an accuracy assessment of the $\mathrm{UAS}_{\mathrm{DSMs}}$ was performed with high-resolution, highaccuracy TLS reference data. While the choice of the study site location in a flat valley floor benefitted the UAS data acquisition (e.g., easy accessibility for MP and RP measurements), it resulted in an unfavourable TLS setup. The only slightly elevated location of the instrument over the valley floor resulted in a large amount of observations with high incidence angles, and caused large TLS footprints and occlusions (45\% of AOI beyond TLS line-of-sight). However, the results showed no correlation between $\mathrm{UAS}_{\mathrm{DSM}}$ error magnitude and footprint size. Therefore, we considered the TLS data valid for $U_{A S}$ DSM accuracy assessment. $\mathrm{UAS}_{\mathrm{DSM}}$ error distribution was nonnormal, but without systematic bias. The skewed error distribution resulted from outliers, which typically occurred at steep rock faces, trees or building façades. Robust accuracy measures were calculated for $\mathrm{UAS}_{\mathrm{DSM}}$ error and error maps interpreted visually. The results showed:

i. Low errors were mostly observed for VIS or NIR UAS imagery acquired with the AOI in full sunlight $\quad(68.3 \% \quad$ quantile $\leq 0.35 \mathrm{~m} ; \quad 95 \%$ quantile $\leq 0.57 \mathrm{~m}$ ).

ii. High errors were determined for VIS UAS imagery acquired with the AOI shadowed or with high amount of blurry imagery ( $>0.41 \mathrm{~m} ;>0.96 \mathrm{~m}$, respectively).

iii. For NIR imagery collected with the AOI shadowed, one flight showed errors in the same range as for imagery collected in full sunlight; a similar scenario in a different flight, however, showed very high errors. Visual interpretation suggested an underlying systematic error (e.g., poor image alignment due to changing illumination caused by shadow moving across AOI during image acquisition).

Ad (2) If UAS imagery was available for two or more points in time, height differences were calculated between the $\mathrm{UAS}_{\mathrm{DSMs}}$. In this case, one 'snowoff' $\mathrm{UAS}_{\mathrm{DSM}}$ was compared to several 'snow-on' $\mathrm{UAS}_{\mathrm{DSMs}}$ to determine relative surface height change, i.e., $\mathrm{UAS}_{\mathrm{SDMs}}$. The accuracy of $\mathrm{UAS}_{\mathrm{SDMs}}$ was assessed with MP data, collected for the February campaigns. The $\mathrm{UAS}_{\mathrm{SDM}}$ error was distributed normally, thus standard accuracy measures were applied. The results show a negative bias in the data, caused by the interaction of vegetation and snow cover (Adams et al. 2016; Bühler et al. 2016). This problem has also been described in comparable studies by other authors (e.g., Marti et al. 2016; Vander Jagt et al. 2015; Nolan et al. 2015). After correction of this bias, $\mathrm{UAS}_{\mathrm{SDM}}$ errors follow a pattern similar to the $\mathrm{UAS}_{\mathrm{DSM}}$ errors $(\mathrm{RMSE}<0.31$ and $>0.39 \mathrm{~m}$ for flights recorded under good and poor illumination conditions, respectively). The results also showed some indication of high QI and low RMS reprojection error being correlated to low $\mathrm{UAS}_{\mathrm{SDM}}$ error.

Ad (3) The precision of snow depth mapping with UAS photogrammetry was assessed by intercomparison of two sets of $\mathrm{UAS}_{\mathrm{SDMs}}$ recorded under similar site-specific settings (VIS imagery acquired with AOI in full sunlight). The results showed that over a small area with negligible intermittent height change, the normally distributed residues were within $0.04 \mathrm{~m}$ (SD) for both the comparisons; over the whole AOI, 
the $68.3 \%$ quantile of the non-normally distributed residues where within \pm 0.25 to $\pm 0.33 \mathrm{~m}$.

UAS-based snow depth mapping provides a reliable source of snow depth information at an unprecedented level of detail (decimetres to centimetres). On-demand UAS surveys at the slope-scale can be performed cost-efficiently to provide details on snow depth distribution and allow visual interpretation of the snow surface with orthophotos. In the presented case, testing different setups and sensors, and evaluating the spatial and temporal variations of accuracy and precision, provides further insight into UAS-based snow depth mapping. However, the employed indirect georeferencing technique proved to be a considerable drawback, because it was very time-consuming, limited the achievable accuracy and reduced the benefits of close-range sensing (Adams et al. 2016). Additionally, the TLS setup showed some weaknesses due to high incidence angles. Further developments could include applying the presented technique to an AOI with a geometric setup more suited to TLS measurements or the use of additional sensors for snow quality, rather than only snow quantity mapping.

\section{Acknowledgements}

This research was funded within the Austrian Academy of Sciences (ÖAW) research programme Earth System Sciences (ESS)-International Geoscience Programme (IGCP)/Federal Ministry of Science, Research and Economy (BMWFW); project RPAS4SNOW. The authors would like to sincerely thank: Johann Zagajsek and his team for support at the test site; Andreas Huber and Armin Graf for supporting the field work; Julia Adams for proofreading the manuscript; both the reviewers and the editor for valuable comments, which helped improve the clarity and quality of this paper.

Open Access This article is distributed under the terms of the Creative Commons Attribution 4.0 International License (http:// creativecommons.org/licenses/by/4.0/), which permits unrestricted use, distribution, and reproduction in any medium, provided you give appropriate credit to the original author(s) and the source, provide a link to the Creative Commons license, and indicate if changes were made.

\section{REFERENCES}

Adams, M. S., Bühler, Y., Boesch, R., Fromm, R., Stoffel, A. \& Ginzler, C. (2016). Investigating the potential of low-cost remotely piloted aerial systems for monitoring the Alpine snow cover (RPAS4SNOW). Final Project Report, ÖAW-Austrian Academy of Sciences, Innsbruck (Austria), pp. 82.

Agisoft LLC. (2016). Agisoft PhotoScan user manual: Professional edition, Version 1.2.

Avanzi, F., Bianchi, A., Cina, A., De Michele, C., Maschio, P., Pagliari, D., Passoni, D. Pinto, L., Piras, M. \& Rossi, L. (2017). Measuring the snowpack depth with unmanned aerial system photogrammetry: Comparison with manual probing and a 3D laser scanning over a sample plot. The Cryosphere Discussion, in review.

Beyers, J. H. M., Sundsbø, P. A., \& Harms, T. M. (2004). Numerical simulation of three-dimensional, transient snow drifting around a cube. Journal of Wind Engineering and Industrial Aerodynamics, 92(9), 725-747.

Bilodeau, F., Gauthier, G., \& Berteaux, D. (2013). The effect of snow cover on lemming population cycles in the Canadian high arctic. Oecologia, 172, 1007-1016.

Boesch, R., Bühler, Y., Ginzler, C., Adams, M. S., Fromm, R. \& Graf. A. (2015). Optimizing channel weights for digital surface models with snow coverage. ISPRS Archives, $X L-3 / W 3$.

Boesch, R., Bühler, Y., Marty, M., \& Ginzler, C. (2016). Comparison of digital surface models for snow depth mapping with UAV and aerial cameras. The International Archives of the Photogrammetry, Remote Sensing and Spatial Information Sciences, XLI-B8, 453-458.

Bühler, Y., Adams, M. S., Boesch, R., \& Stoffel, A. (2016). Mapping snow depth in alpine terrain with unmanned aerial systems (UAS): Potential and limitations. The Cryosphere, 10, 1075-1088.

Bühler, Y., Adams, M., Stoffel, A., \& Boesch, R. (2017). Photogrammetric reconstruction of homogenous snow surfaces in alpine terrain applying near infrared UAS imagery. International Journal of Remote Sensing, 38, 8-10.

Bühler, Y., Meier, L., \& Ginzler, C. (2015). Potential of operational high spatial resolution near-infrared remote sensing instruments for snow surface type mapping. IEEE Geoscience and Remote Sensing Letters, 12(4), 821-825.

Cline, D. W., Bales, R. C., \& Dozier, J. (1998). Estimating the spatial distribution of snow in mountain basins using remote sensing and energy balance modeling. Water Resources Research, 34(5), 1275-1285.

Colomina, I., \& Molina, P. (2014). Unmanned aerial systems for photogrammetry and remote sensing: A review. ISPRS Journal of Photogrammetry and Remote Sensing, 92, 79-97.

De Michele, C., Avanzi, F., Passoni, D., Barzaghi, R., Pinto, L., Dosso, P., et al. (2016). Using a fixed-wing UAS to map snow depth distribution: An evaluation at peak accumulation. The Cyrosphere, 10, 511-522.

Decaulne, A. (2007). Snow-avalanche and debris-flow hazards in the fjords of north-western Iceland, mitigation and prevention. Natural Hazards, 41(1), 81-98.

Deems, J. S., Painter, T. H., \& Finnegan, D. C. (2013). Lidar measurement of snow depth: A review. Journal of Glaciology, 59, 467-479. 
Dietz, A. J., Kuenzer, C., Gassner, U., \& Dech, S. (2012). Remote sensing of snow-A review of available methods. International Journal of Remote Sensing, 33(13), 4094-4134.

Dozier, J., \& Painter, T. H. (2004). Multispectral and hyperspectral remote sensing of alpine snow properties. Annual Review of Earth and Planetary Sciences, 32, 465-494.

Durand, Y., Guyomarc'h, G., Mérindol, L., \& Corripio, J. G. (2005). Improvement of a numerical snow drift model and field validation. Cold Regions Science and Technology, 43(1-2), 93-103.

Elder, K., Dozier, J., \& Michaelsen, J. (1991). Snow accumulation and distribution in an alpine watershed. Water Resources Research, 27(7), 1541-1552.

Elder, K., Rosenthal, W., \& Davis, R. E. (1998). Estimating the spatial distribution of snow water equivalence in a montane watershed. Hydrological Processes, 12(10-11), 1793-1808.

Fabris, M., \& Pesci, A. (2005). Automated DEM extraction in digital aerial photogrammetry: Precisions and validation for mass movement monitoring. Annales Geophysicae, 48, 973-988.

Fahrmeir, L., Künstler, R., Pigeot, I., \& Tutz, G. (2011). Statistik: Der Weg zur Datenanalyse (7th ed.). Heidelberg: Springer.

Fierz, C., Armstrong, R. L., Durand, Y., Etchevers, P., Greene, E., McClung, D. M., et al. (2009). The International classification for seasonal snow on the ground. Paris, France: IACS, UNESCO.

Fischer, J.-T., Kofler, A., Fellin, W., Granig, M., \& Kleemayr, K. (2015). Multivariate parameter optimization for computational snow avalanche simulation. Journal of Glaciology, 61(229), 875-888.

Foppa, N., Stoffel, A., \& Meister, R. (2007). Synergy of in situ and space borne observation for snow depth mapping in the Swiss Alps. International Journal of Applied Earth Observation and Geoinformation, 9, 294-310.

Fras, K. M., Kerin, A., Mesarič, M., Peterman, V \& Grigillo, D. (2016). Assessment of the quality of digital terrain model produced from unmanned aerial system imagery. In The international archives of the photogrammetry, remote sensing and spatial information sciences, XLI-B1, XXIII ISPRS Congress, 12-19 July 2016, Prague, Czech Republic.

Fuchs, S., Thöni, M., McAlpin, M. C., Gruber, U., \& Bründl, M. (2007). Avalanche hazard mitigation strategies assessed by cost effectiveness analyses and cost benefit analyses-Evidence from Davos, Switzerland. Natural Hazards, 41(1), 113-129.

Furukawa, Y. \& Ponce, J. (2009). Dense 3D motion capture for human faces. In Proceedings/CVPR, IEEE computer society conference on computer vision and pattern recognition.

Gini, R., Pagliari, D., Passoni, D., Pinto, L., Sona, G., Dosso, P. (2013). UAV photogrammetry: block triangulation comparisons. International Archives of the Photogrammetry, Remote Sensing and Spatial Information Sciences, XL-1/W2, 157-162.

Ginzler, C., Marty, M., \& Bühler, Y. (2013). Grossflächige hochaufgelöste Schneehöhenkarten aus digitalen Stereoluftbildern. DGPF Tagungsband, 22, 71-78.

Grünewald, T., Schirmer, M., Mott, R., \& Lehning, M. (2010). Spatial and temporal variability of snow depth and ablation rates in a small mountain catchment. The Cryosphere, 4, 215-225.

Haala, N. (2011). Multiray photogrammetry and dense image matching. In D. Fritsch (Ed.), Proceedings of photogrammetric week 2011, Wichmann/VDE Verlag, Berlin \& Offenbach (pp. 185-195).

Harder, P., Schirmer, M., Pomeroy, J., \& Helgason, W. (2016). Accuracy of snow depth estimation in mountain and prairie environments by an unmanned aerial vehicle. The Cryosphere, $10,2559-2571$.

Hartzell, P. J., Gadomski, P. J., Glennie, C. L., Finnegan, D. C., \& Deems, J. S. (2015). Rigorous error propagation for terrestrial laser scanning with application to snow volume uncertainty. Journal of Glaciology, 61(230), 1147-1158.

Harwin, S., Lucieer, A., \& Osborn, J. (2015). The impact of the calibration method on the accuracy of point clouds derived using unmanned aerial vehicle multi-view stereopsis. Remote Sensing, 7(9), 11933-11953.

Helbig, N., van Herwijnen, A., \& Jonas, T. (2015). Forecasting wet-snow avalanche probability in mountainous terrain. Cold Regions Science and Technology, 120, 219-226.

Höhle, J., \& Höhle, M. (2009). Accuracy assessment of digital elevation models by means of robust statistical methods. ISPRS Journal of Photogrammetry and Remote Sensing, 64(4), 398-406.

Holub, M., \& Fuchs, S. (2009). Mitigating mountain hazards in Austria-Legislation, risk transfer and awareness building. Natural Hazards and Earth System Sciences, 9, 523-537.

Hugenholtz, C. H., Whitehead, K., Brown, O., Barchyn, T. E., Moorman, B. J., LeClair, A., et al. (2013). Geomorphological mapping with a small unmanned aircraft system (sUAS): Feature detection and accuracy assessment of a photogrammetrically derived digital terrain model. Geomorphology, 194, 16-24.

Immerzeel, W. W., Kraaijenbrink, P. D. A., Shea, J. M., Shrestha, A. B., Pellicciotti, F., Bierkens, M. F. P., et al. (2014). Highresolution monitoring of Himalayan glacier dynamics using unmanned aerial vehicles. Remote Sensing of Environment, 150, 93-103.

Jörg, P., Fromm, R., Sailer, R. \& Schaffhauser, A. (2006). Measuring snow depth with a terrestrial laser ranging system. In ISSW international snow science workshop 2006, Telluride, Colorado, Proceedings (pp. 452-460).

Klemas, V. V. (2015). Coastal and environmental remote sensing from unmanned aerial vehicles: An overview. Journal of Coastal Research, 31(5), 1260-1267.

Koenderink, J. J., \& van Doorn, A. J. (1991). Affine structure from motion. Journal of the Optical Society of America, 8(2), 377-385.

Lendzioch, T., Langhammer, J. \& Jenicek, M. (2016). Tracking forest and open area effects on snow accumulation by unmanned aerial vehicle photogrammetry. In The international archives of the photogrammetry, remote sensing and spatial information sciences, XLIB1, XXIII ISPRS Congress, 12-19 July 2016, Prague, Czech Republic, 2016.

Mancini, F., Dubbini, M., Gattelli, M., Stecchi, F., Fabbri, S., \& Gabbianelli, G. (2013). Unmanned aerial vehicles (UAV) for high-resolution reconstruction of topography: The structure from motion approach on coastal environments. Remote Sensing, 5, 6880-6898.

Margreth, S., \& Romang, S. (2010). Effectiveness of mitigation measures against natural hazards. Cold Regions Science and Technology, 64(2), 199-207.

Marti, R., Gascoin, S., Berthier, E., de Pinel, M., Houet, T., \& Laffly, D. (2016). Mapping snow depth in open alpine terrain from stereo satellite imagery. The Cryosphere, 10, 1361-1380.

Maune, D. F. (2007). Digital elevation model technologies and applications: The DEM user manual (2nd ed.). Bethesda: ASPRS Publications. 
Miziński, B., \& Niedzielski, T. (2017). Fully-automated estimation of snow depth in near real time with the use of unmanned aerial vehicles without utilizing ground control points. Cold Regions Science and Technology, 138, 63-72.

Morgenthal, G., \& Hallermann, N. (2016). Quality assessment of unmanned aerial vehicle (UAV) based visual inspection of structures. Advances in Structural Engineering, 17(3), 289-302.

Müller, J., Gärtner-Roer, I., Thee, P., \& Ginzler, C. (2014). Accuracy assessment of airborne photogrammetrically derived high resolution digital elevation models in a high mountain environment. ISPRS Journal of Photogrammetry and Remote Sensing, 98, 58-69.

Nex, F., \& Remondino, F. (2013). UAV for 3D mapping applications: A review. Applied Geomatics, 6(1), 1-15.

Nolan, M., Larsen, C., \& Sturm, M. (2015). Mapping snow depth from manned aircraft on landscape scales at centimeter resolution using structure-from-motion photogrammetry. Cryosphere, 9, 1445-1463.

Nolin, A. W. (2010). Recent advances in remote sensing of seasonal snow. Journal of Glaciology, 56(200), 1141-1150.

Nolin, A. W., \& Dozier, J. (2000). A Hyperspectral method for remotely sensing the grain size of snow. Remote Sensing of Environment, 74(2), 207-216.

Painter, T. H., Berisford, D. F., Boardman, J. W., Bormann, K. J., Deems, J. S., Gehrke, F., et al. (2016). The airborne snow observatory: Fusion of scanning lidar, imaging spectrometer, and physically-based modeling for mapping snow water equivalent and snow albedo. Remote Sensing of the Environment, 184, 139-152.

Peng, S., Piao, S., Ciais, P., \& Fang, J. (2010). Change in winter snow depth and its impacts on vegetation in China. Global Change Biology, 16, 3004-3013.

Prokop, A. (2008). Assessing the applicability of terrestrial laser scanning for spatial snow depth measurements. Cold Regions Science and Technology, 54(3), 155-163.

Prokop, A., Schirmer, M., Rub, M., Lehning, M., \& Stocker, M. (2008). A comparison of measurement methods: Terrestrial laser scanning, tachymetry and snow probing, for the determination of the spatial snow depth distribution on slopes. Annals of Glaciology, 49, 210-216.

Rees, W. G. (2006). Remote sensing of snow and ice. Boca Raton, FL: CRC Press.

Riegl. (2006). Long-range laser profile measuring system LPM 98-2K-Technical documentation \& user's instructions.

Riegl. (2010). Long-range laser profile measuring system LPM321-Technical documentation \& user's instructions.

Schaffhauser, A., Adams, M., Fromm, R., Joerg, P., Luzi, G., Noferini, L., et al. (2008). Remote sensing based retrieval of snow cover properties. Cold Regions Science and Technology, $54,164-175$.
Schaffhauser, A. \& Fromm, R. (2008). General statements on the temporal and spatial development of snow cover during snow fall periods particularly with consideration of snow drift. Deliverable D 7.5 in the project GALAHAD Advanced Remote Monitoring Techniques for Glaciers, Avalanches and Landslides Hazard Mitigation.

Schöber, J., Schneider, K., Helfricht, K., Schattan, P., Achleitner, S., Schöberl, F., et al. (2014). Snow cover characteristics in a glacierized catchment in the Tyrolean Alps-improved spatially distributed modelling by usage of Lidar data. Journal of Hydrology, 519, 3492-3510.

Sona, G., Pinto, L., \& Pagliari, D. (2014). Experimental analysis of different software packages for orientation and digital surface modelling from UAV images. Earth Science Informatics, 7(2), 97-107.

Teich, M., Fischer, J.-T., Feistl, T., Bebi, P., Christen, M., \& GrêtRegamey, A. (2014). Computational snow avalanche simulation in forested terrain. Natural Hazards and Earth System Sciences Discussions, 14, 2233-2248.

Tonkin, T., Midgley, N. G., Graham, D. J., \& Ladadz, J. (2014). The potential of small unmanned aircraft systems and structurefrom-motion for topographic surveys: A test of emerging integrated approaches at Cwm Idwal, North Wales. Geomorphology, 226, 35-43.

Turner, D., Lucieer, A., \& de Jong, S. M. (2015). Time series analysis of landslide dynamics using an unmanned aerial vehicle (UAV). Remote Sensing, 7(2), 1736-1757.

Vander Jagt, B., Lucieer, A., Wallace, L., Turner, D., \& Durand, M. (2015). Snow depth retrieval with UAS using photogrammetric techniques. Geosciences, 5, 264-285.

Verhoeven, G. (2011). Taking computer vision aloft-Archaeological three-dimensional reconstructions from aerial photographs with photoscan. Archaeological Prospection, 18, 67-73.

Vernay, M., Lafaysse, M., Mérindol, L., Giraud, G., \& Morin, S. (2015). Ensemble forecasting of snowpack conditions and avalanche hazard. Cold Regions Science and Technology, 120, 251-262.

Whitehead, K., \& Hugenholtz, C. H. (2014). Remote sensing of the environment with small unmanned aircraft systems (UASs), part 1: A review of progress and challenges. Journal of Unmanned Vehicle Systems, 2(3), 69-85.

Willmott, C. J., \& Matsuura, K. (2006). On the use of dimensioned measures of error to evaluate the performance of spatial interpolators. International Journal of Geographical Information Science, 20(1), 89-102.

Zongjian, L., Guozhong, S. \& Feifei, X. (2012). UAV borne low altitude photogrammetry system. In International archives of the photogrammetry, remote sensing and spatial information sciences, XXXIX-B1, 2012 XXII ISPRS Congress, 25 August-01 September 2012, Melbourne, Australia. 